TREE-1368

Distribution Category:

UC-70

\title{
SODIUM REMOVAL FROM HALLAM REACTOR COMPONENTS
}

L. Knox Huntsman

Richard H. Meservey

EG\&G Idaho, Inc.

Idaho Falls, Idaho 83401

Published August 1979

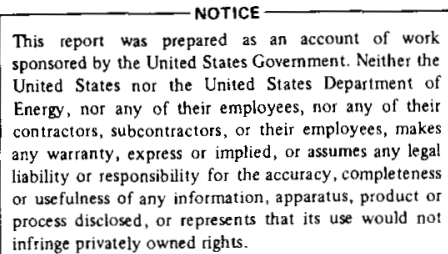

This document is

PREPARED FOR THE

U.S. DEPARTMENT OF ENERGY IDAHO OPERATIONS OFFICE

UNDER CONTRACT NO. DE-AC07-76ID01570

PUBLICLY RELEASABLE
Bamy Sleeb
Authorizing Official
Date: $11.9 \cdot 06$




\section{DISCLAIMER}

This report was prepared as an account of work sponsored by an agency of the United States Government. Neither the United States Government nor any agency Thereof, nor any of their employees, makes any warranty, express or implied, or assumes any legal liability or responsibility for the accuracy, completeness, or usefulness of any information, apparatus, product, or process disclosed, or represents that its use would not infringe privately owned rights. Reference herein to any specific commercial product, process, or service by trade name, trademark, manufacturer, or otherwise does not necessarily constitute or imply its endorsement, recommendation, or favoring by the United States Government or any agency thereof. The views and opinions of authors expressed herein do not necessarily state or reflect those of the United States Government or any agency thereof. 


\section{DISCLAIMER}

Portions of this document may be illegible in electronic image products. Images are produced from the best available original document. 


\section{ACKNOWLEDGMENTS}

The work described herein was performed by EG\&G, Idaho, Inc., with consulting assistance from Allied Chemical Corporation (ACC), under the auspices of the Department of Energy (DOE). The authors wish to thank J. D. Frasca for an excellent job of handling the overall project engineering support, D. K. Wang, D. L. Davenport, and A. F. Fanous for the design engineering support, L. C. Hammer and B. A. Winters for the system fabrication and operations, and the EG\&G Safety Division, and in particular D. J. Riffe, C. D. Sorensen, and J. D. Burtenshaw for their support in safety matters. In addition, the authors would also like to acknowledge Dr. R. R. Hammer and Dr. L. C. Lewis of ACC for helping to make the Hallam D\&D project successful. 


\begin{abstract}
This report discusses the removal of sodium from major components of the Hallam Nuclear Power Facility. This facility contained the experimental reactor used to test the feasibility of sodium coolant.

The Idaho Operations Office of the Department of Energy assigned EG\&G Idaho, Inc., the task of carrying out this decontamination and decommissioning program at the Idaho National Engineering Laboratory (INEL).

Since their shipment to the INEL from Lincoln, Nebraska in 1968, the Hallam Reactor components had been stored in inert nitrogen to prevent the sodium in the components from reacting with moisture in the air.

The procedure used to react the sodium in the components and to decontaminate them is discussed. Problems and unusual occurrences in the decontamination and decommissioning process are also reported.
\end{abstract}




\section{CONTENTS}

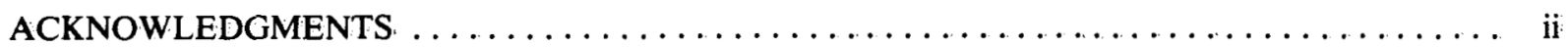

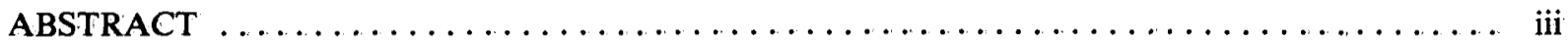

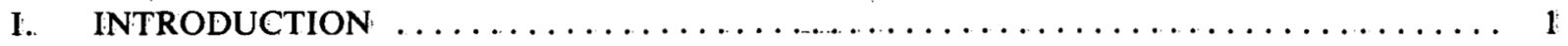

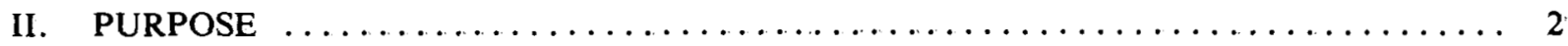

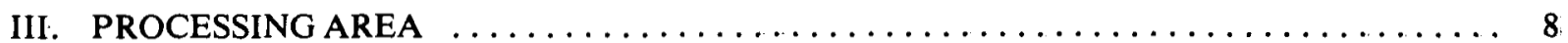

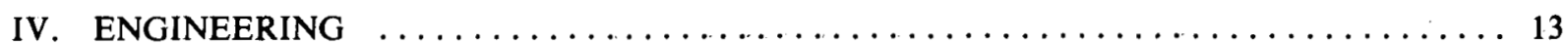

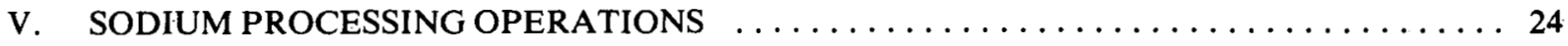

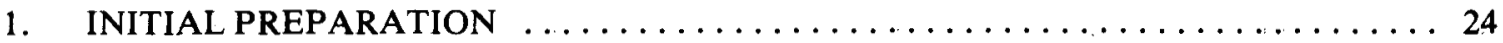

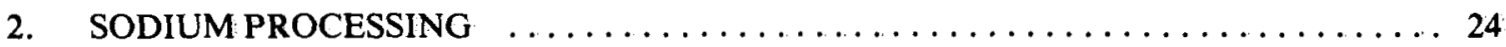

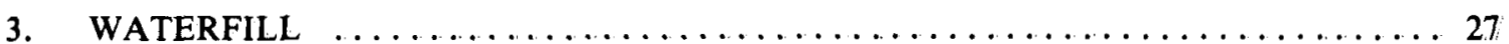

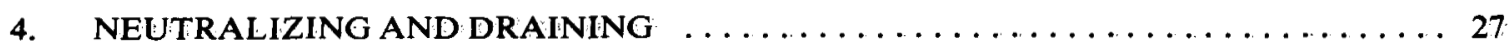

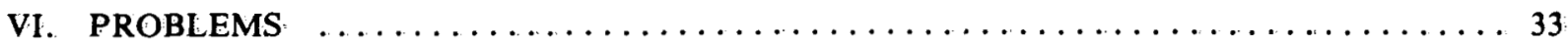



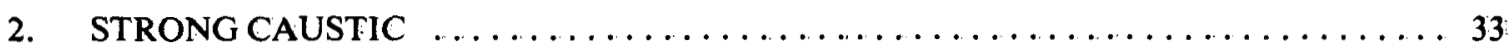

3. CONCENTRATED SULFURIC ACID $\ldots \ldots \ldots \ldots \ldots \ldots \ldots \ldots \ldots \ldots \ldots \ldots$

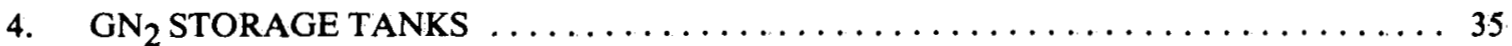

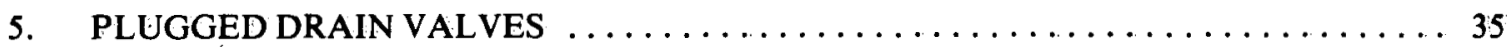

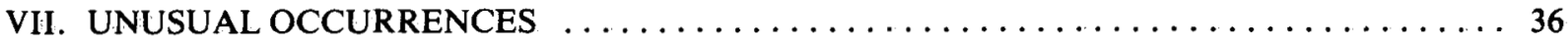

VIII. POSTPROCESSING INSPECTION $\ldots \ldots \ldots \ldots \ldots \ldots \ldots \ldots \ldots \ldots \ldots \ldots \ldots \ldots \ldots \ldots$

IX. DISPOSITION OF THE COMPONENTS $\ldots \ldots \ldots \ldots \ldots \ldots \ldots \ldots \ldots \ldots \ldots \ldots \ldots$

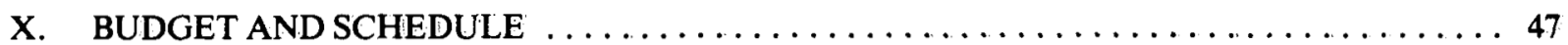

XI. CONCLUSIONS AND RECOMMENDATIONS $\ldots \ldots \ldots \ldots \ldots \ldots \ldots \ldots \ldots \ldots \ldots$

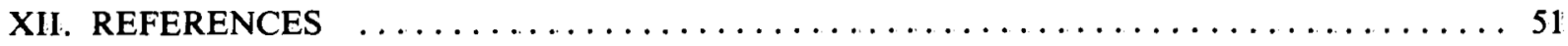

\section{FIGURES}



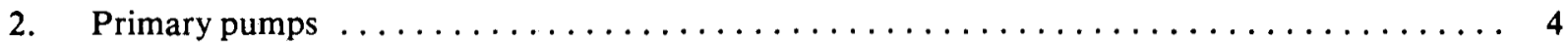


3. Steam generator evaporators $\ldots \ldots \ldots \ldots \ldots \ldots \ldots \ldots \ldots \ldots \ldots \ldots \ldots \ldots \ldots$

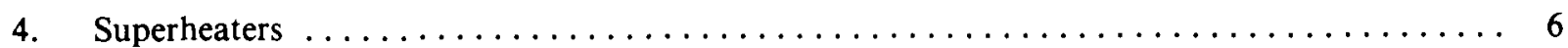

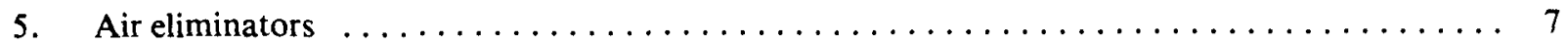

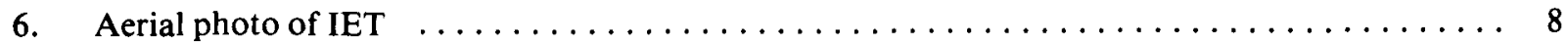

. 7. Site plan for Hallam components $\ldots \ldots \ldots \ldots \ldots \ldots \ldots \ldots \ldots \ldots \ldots \ldots \ldots \ldots \ldots$

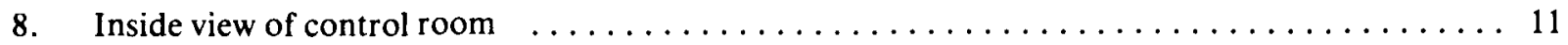

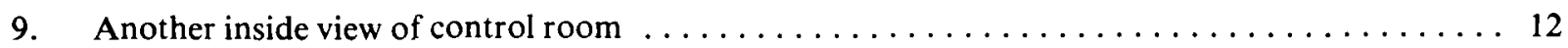

10. Hallam processing flow path for noncontaminated components $\ldots \ldots \ldots \ldots \ldots \ldots \ldots \ldots$

11. Hallam processing flow path for contaminated components $\ldots \ldots \ldots \ldots \ldots \ldots \ldots \ldots$



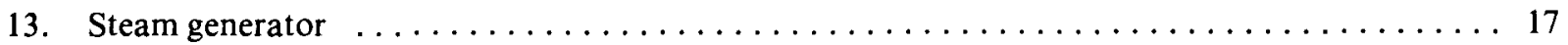

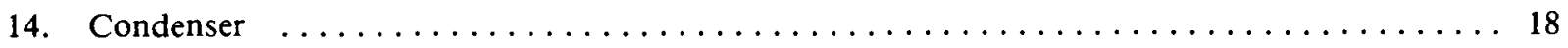

15. View of processing system, demister, scrubber, separator,

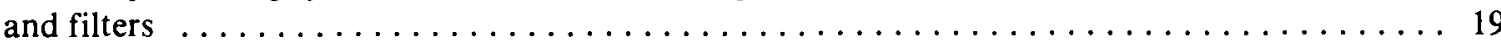

16. View of processing system, filters, separator, scrubber,

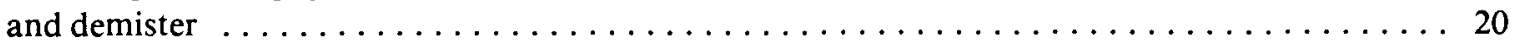

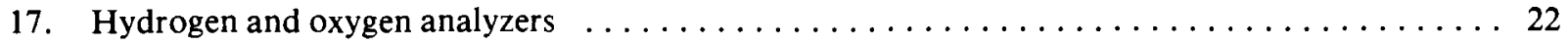

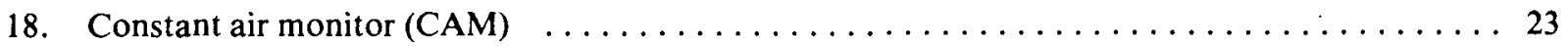

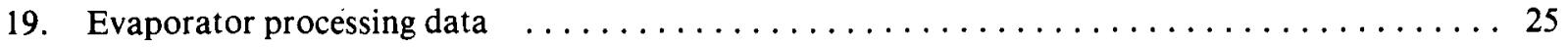

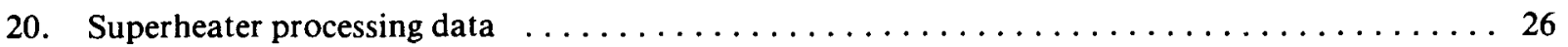

21. Intermediate heat exchanger processing data $\ldots \ldots \ldots \ldots \ldots \ldots \ldots \ldots \ldots \ldots \ldots \ldots$

22. Processing area showing the 1514-1 (400-gal) acid storage

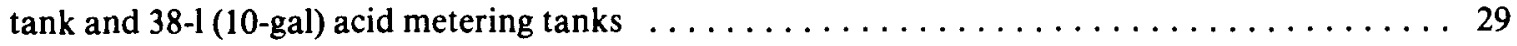

23. Another view of the $1514-1$ (400-gal) and the 38-1 (10-gal)

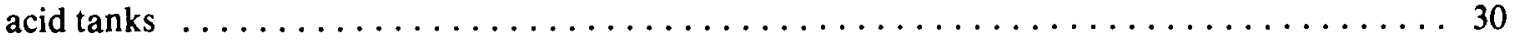

24. Apparatus used to remove sodium from plugged valves $\ldots \ldots \ldots \ldots \ldots \ldots \ldots \ldots \ldots$

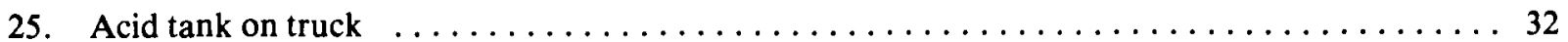

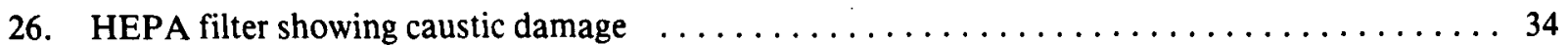

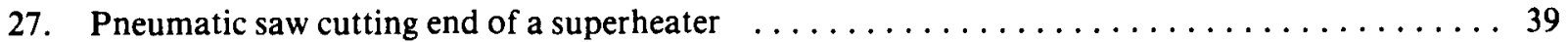




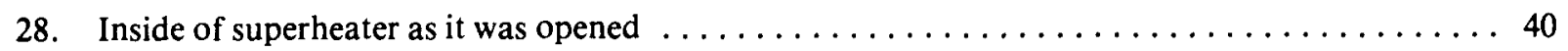

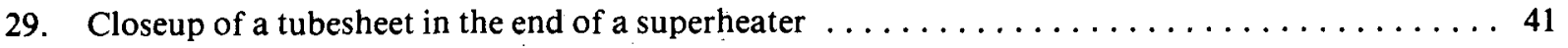

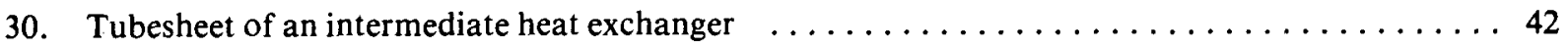

31. Section through intermediate heat exchanger tubes $\ldots \ldots \ldots \ldots \ldots \ldots \ldots \ldots \ldots \ldots \ldots$

32. An array of bellows assemblies containing unreacted sodium $\ldots \ldots \ldots \ldots \ldots \ldots \ldots \ldots$

33. Bellows assembly sectioned to show unreacted sodium $\ldots \ldots \ldots \ldots \ldots \ldots \ldots \ldots \ldots$

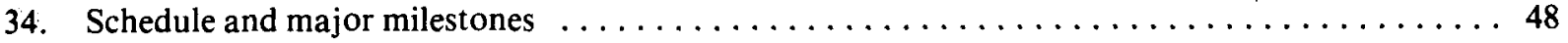



\section{TABLES}

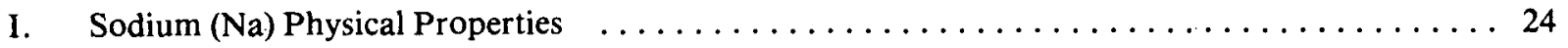

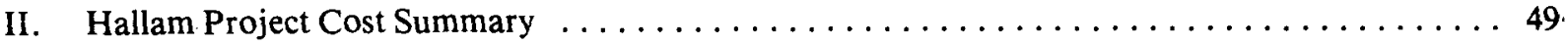




\section{SODIUM REMOVAL FROM HALLAM REACTOR COMPONENTS}

\section{INTRODUCTION}

The Hallam Nuclear Power Facility (HNPF) project was authorized in 1957 by the U.S. Atomic Energy Commission (USAEC). The facility was operated by the Consumers Public Power District of Nebraska at their Sheldon Station site 20 miles south of Lincoln, Nebraska.

The USAEC was the owner, Atomics International (AI) the designer, Bechtel Corporation the architect engineer, and Peter Kiewit and Sons the constructor of the facility. Plant construction started in April 1959.

The reactor used a slightly enriched $(3.6 \%)$ uranium fuel, graphite moderator, and sodium $(\mathrm{Na})$ coolant. The net efficiency was $31.6 \%$. The nominal rating of the plant was $75 \mathrm{MW}$.

The design power of the reactor was $240 \mathrm{MW}$, and the heat generated was transmitted to a primary sodium system at approximately $507^{\circ} \mathrm{C}$. The primary sodium system consisted of three primary loops, each containing two intermediate heat exchangers (IHXs). Each pair of IHXs had a secondary sodium loop which transmitted heat to a steam generating unit. The plant was designed to produce $320000 \mathrm{~kg} / \mathrm{hr}$ of steam at $440^{\circ} \mathrm{C}$ and $5513 \mathrm{kPa}(800 \mathrm{psig}$ ). Sodium coolant was introduced to the primary and secondary systems in 1961, and preoperational testing was started. Criticality was achieved August 25, 1962, and full power was attained in July of 1963. During power operation from July 1963 to the last plant shutdown in October 1964, the average reactor power was about $90 \mathrm{MWt}$. Two IHXs eventually developed primary-tosecondary side $\mathrm{Na}$ leaks. By that time, however, the plant had proven that $\mathrm{Na}$ reactor technology was possible. The expense of downtime and replacing the IHXs proved to be too great, however, and a decision was made to shut the plant down.

The facility was dismantled between 1964 and 1968 by AI $^{1}$. At that time the IHXs, evaporators, superheaters, eliminators, sodium pump casings, and various other components from the HNPF were shipped to the Idaho National Engineering Laboratory (INEL) for storage. Since then they have been in protective storage at the Test Area North (TAN) hangar building.

During the interim storage time at TAN, one 1HX, which was known to have developed tube leaks, was examined. The heat exchanger was cut in half, and the tubes were examined ${ }^{2}$. The heat exchanger is currently buried at the Radioactive Waste Management Complex (RWMC) at the INEL.

Storage of the components required that they be maintained under an inert gas (nitrogen) purge to prevent the sodium from reacting with moisture in the air. This was costly and time consuming. The presence of the Hallam components in the hangar building with the Loss-of-Fluid Test (LOFT) reactor control center also presented an undesirable situation. Since other indoor storage for these large components was not available, and outside storage was not acceptable, the decision was made to remove and stabilize the sodium and dispose of the components. 


\section{PURPOSE}

The Idaho Operations Office (ID), of the Department of Energy (DOE) has assigned to EG\&G Idaho, Inc., the responsibility to carry out the Administration's Decontamination and Decommissioning (D\&D) Program at the INEL.

The Hallam Reactor components have been identified as meeting the intent of established criteria for D\&D work. These criteria are:

(1) The components are radioactively contaminated to the extent that they cannot be decontaminated without Health Physics controls

(2) The components are surplus to the identifiable needs of any DOE program.

Although these components do not meet the criteria of "fixed site location," they were included in D\&D assignments by prior agreement.

A program to remove sodium from the Hallam components was proposed in EG\&G Schedule 189c ID 6209A, entitled "Disposition of Surplus. INEL Contaminated Facilities." The program provided for sodium removal and disposition of the Hallam components. Therefore, the purpose of this project was to process sodium in the excessed Hallam Reactor components, to perform destructive examination of the various components, and to dispose of them in an appropriate manner at the conclusion of the project. The components consist of:

(1) Five intermediate heat exchangers (IHXs): See Figure 1.

(2) Three primary pumps (disassembled). See Figure 2.

(3) Three steam generator evaporators. See Figure 3.

(4) Three superheaters. See Figure 4.

Note: three air eliminators also accompanied the above components. However, the eliminators did not contain any Na and were taken to the Central Facility Area (CFA) at INEL for disposal as surplus property. (See Figure 5.)

In order to accomplish the above, a system was designed and fabricated to react the $\mathrm{Na}$ in the components. The reaction was accomplished by carefully introducing small quantities of steam into an inert atmosphere $\left(\mathrm{GN}_{2}\right)$ and then passing this aqueous nitrogen through the components.

Of the 14 components, five IHXs required processing both the primary and secondary sides. Thus, there are a total of 19 components to be processed. 


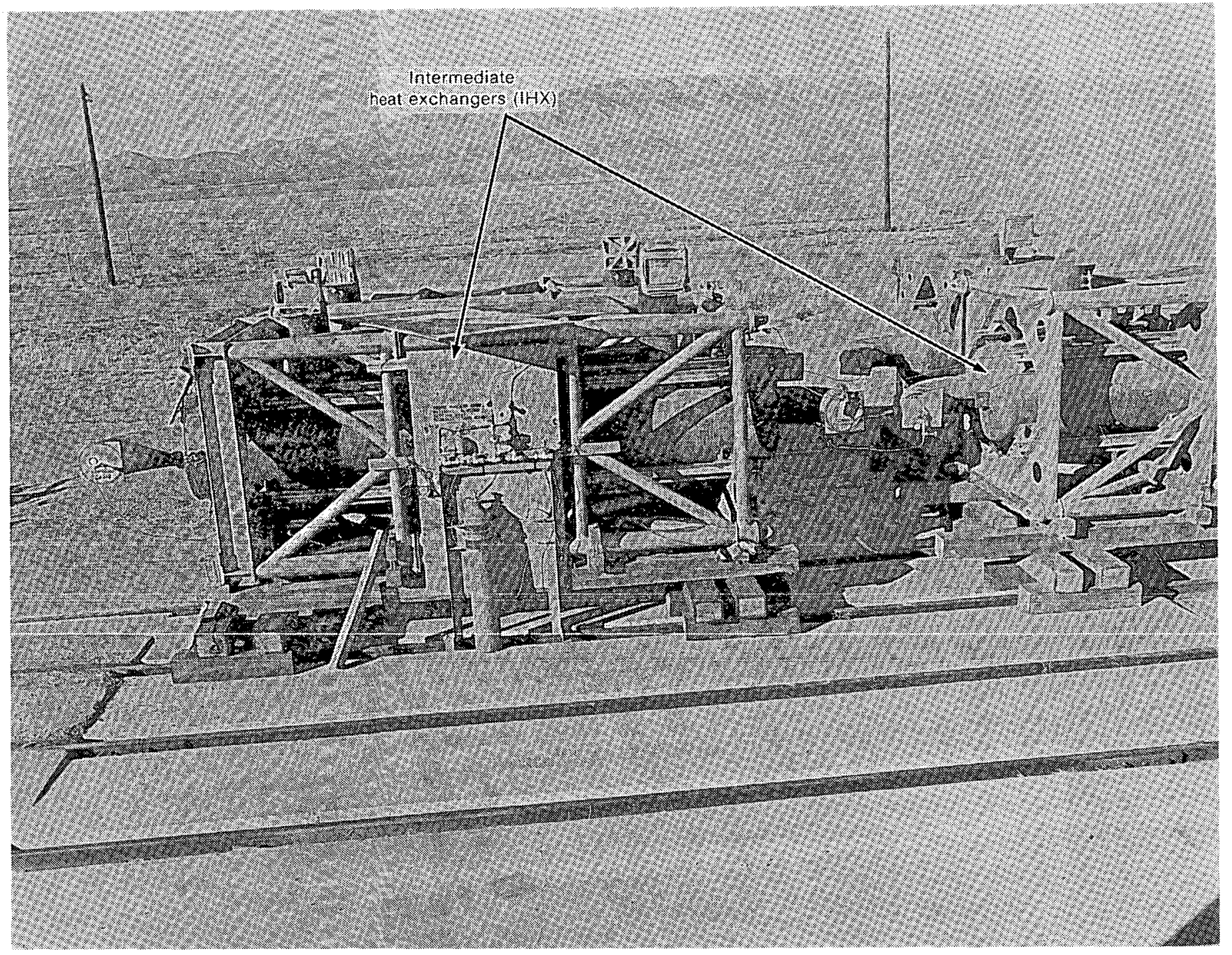

Fig. 1 Intermediate heat exchangers. 


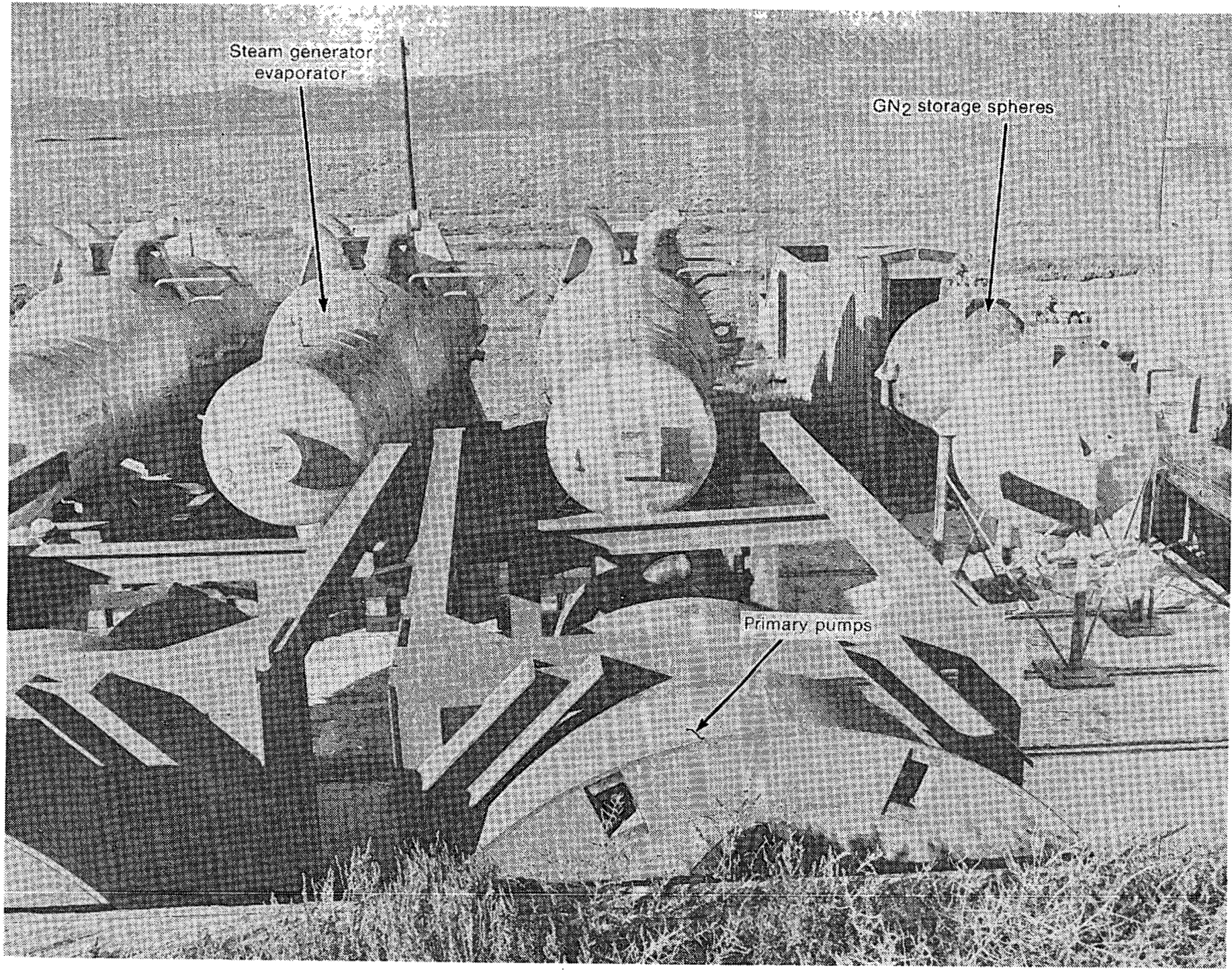

Fig. 2 Primary pumps. 




Fig. 3 Steam generator evaporators. 


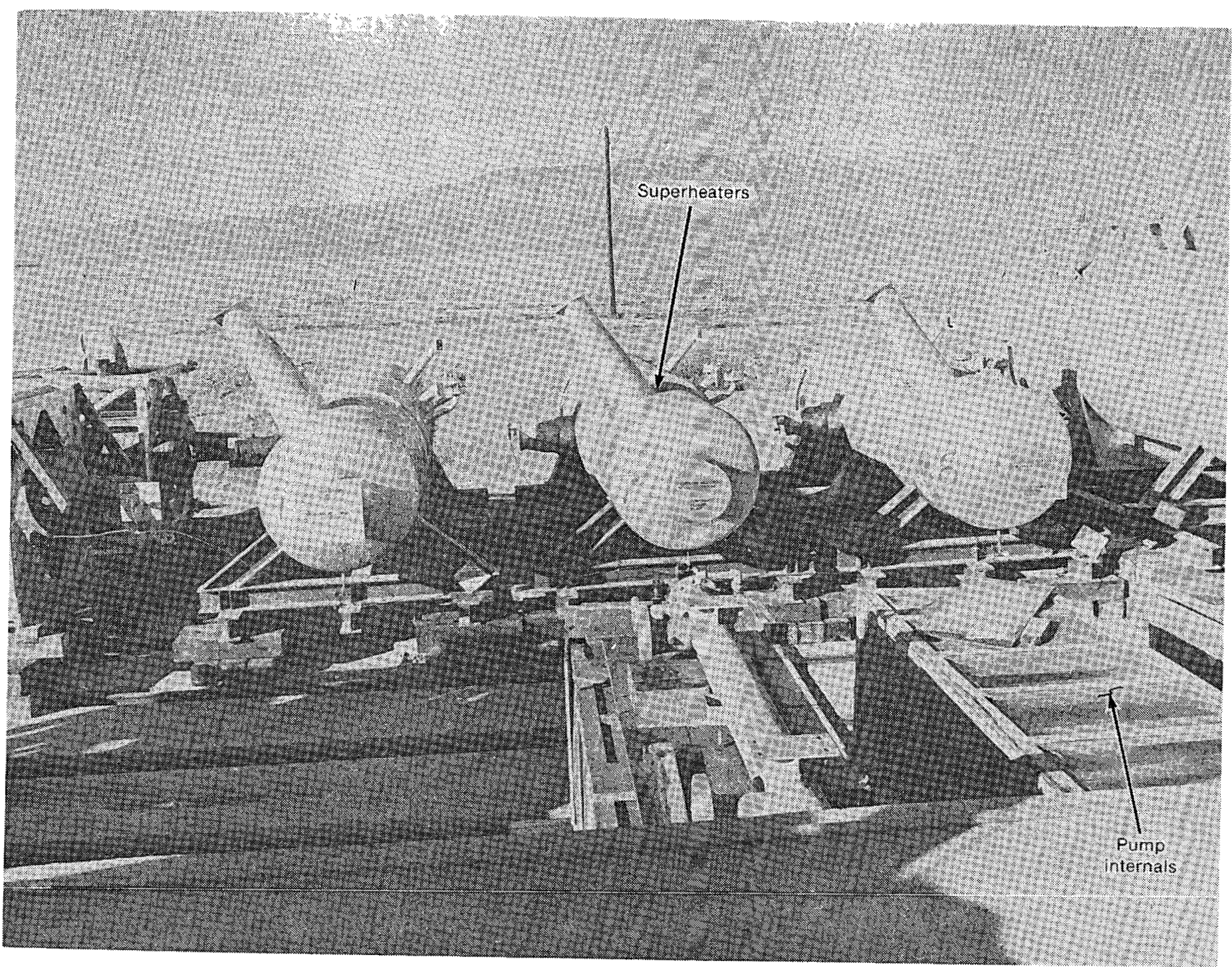

Fig. 4 Superheaters.

- 


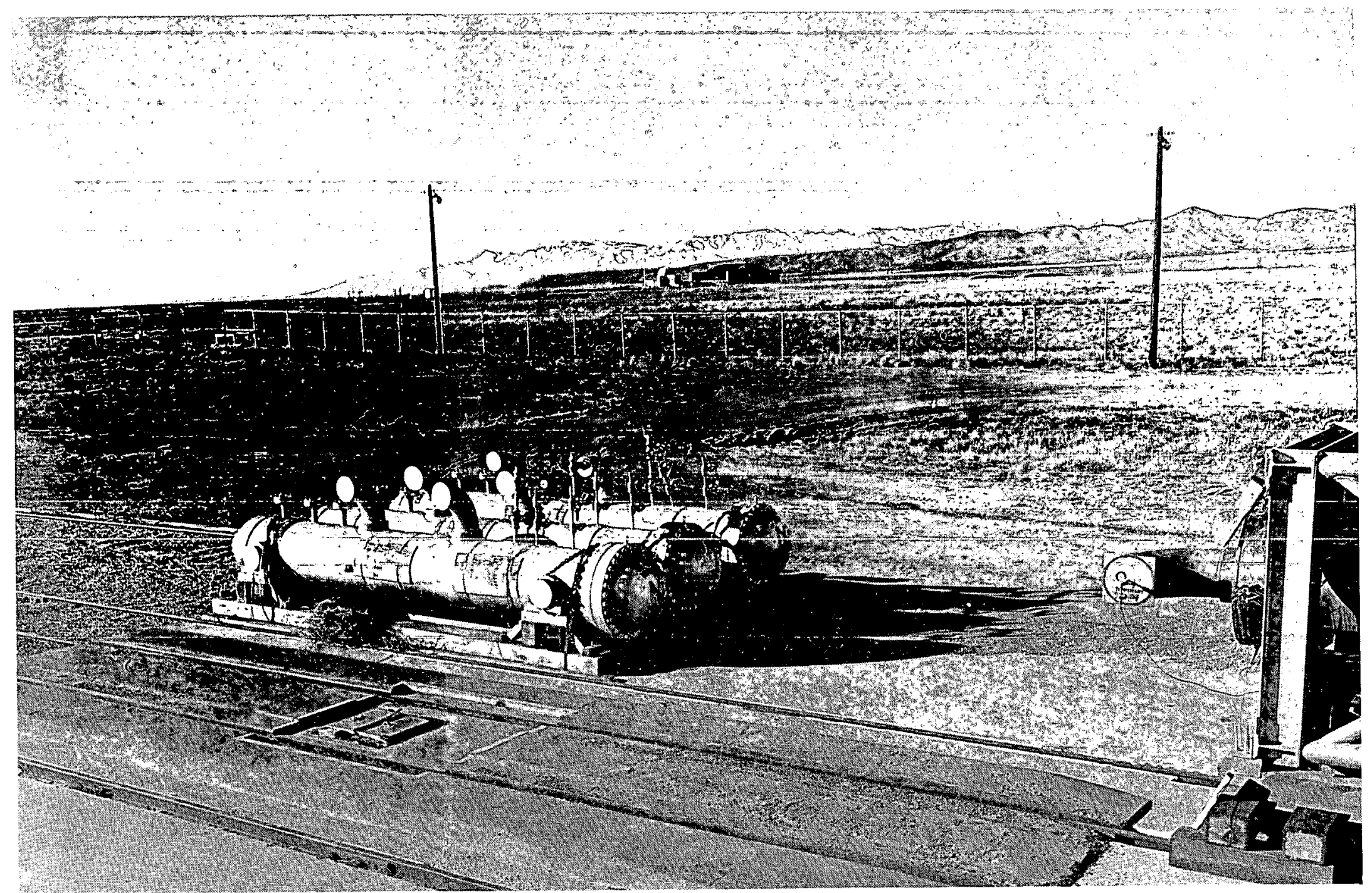

Fig. 5 Air eliminators. 


\section{PROCESSING AREA}

The components were moved from the TAN hangar building to the Initial Engine Test (IET) facility also located at TAN. The IET facility was reactivated to the extent of providing a heated indoor operations area, change area, emergency showers, and all other accommodations necessary for a safe operation of this project. Specifically, the electrical power, water, phones, and emergency alarms were reactivated. Heaters were installed in the operations room, working area, change room, and lunch room. An aerial photo of the IET facility is shown in Figure 6. Although the exhaust stack is the dominate feature of this area, the Hallam components can be seen located at the processing area.

The IET facility was selected to process the components for the following reasons.

(1) The IET facility has a large concrete slab which provides an excellent area to set the components on. Their arrangement on the pad is shown schematically in Figure 7.

(2) A control room could be located in an underground room adjacent to the concrete slab. This provides the operating crew additional safety from any hazards which might develop on the pad. Figures 8 and 9 show the insides of the control room.

(3) Much of the piping, valves, and equipment used in the process system were obtained from the IET as excess equipment.

(4) The cost of reactivating the IET was considerably less than establishing temporary facilities elsewhere. 


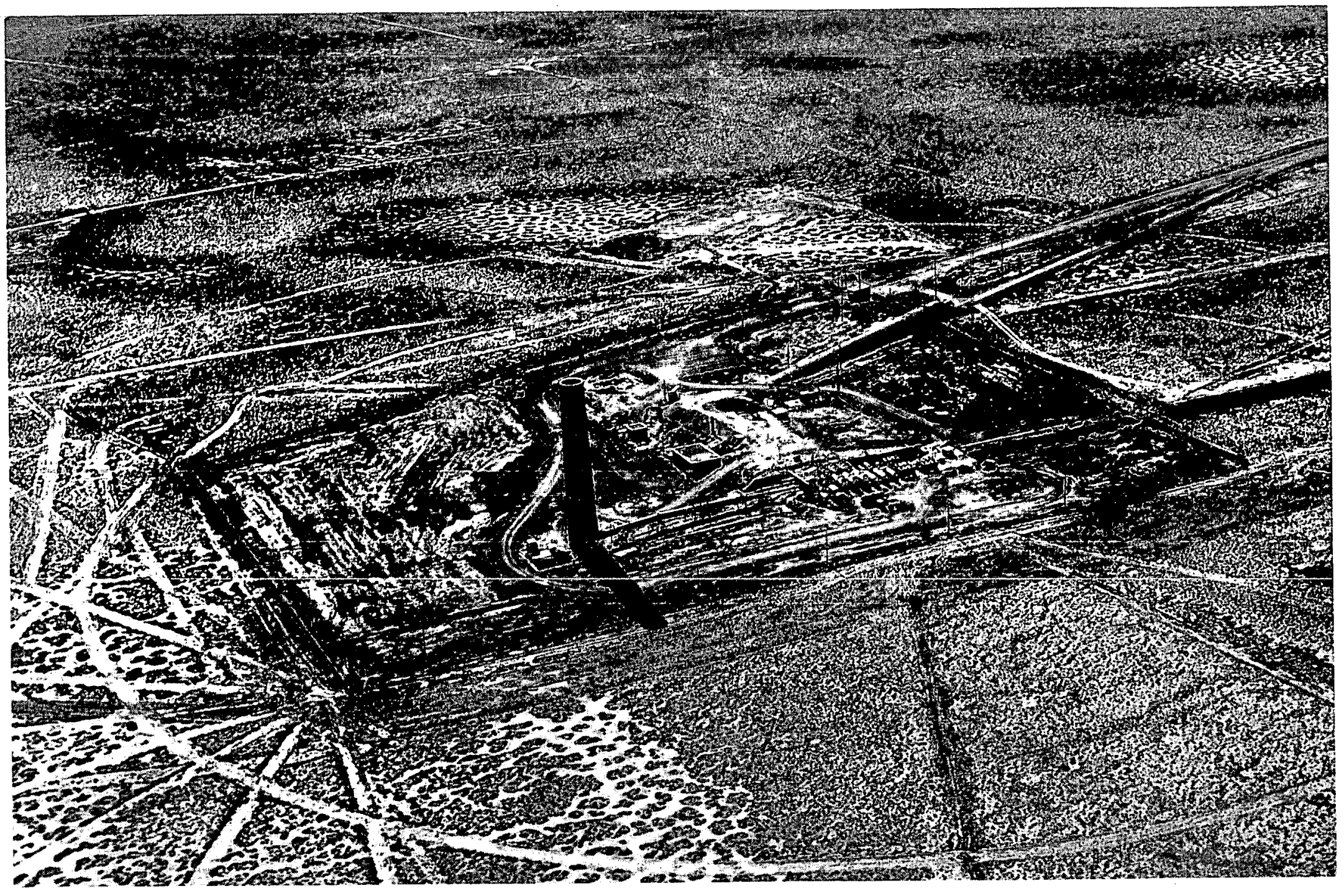

Fig. 6 Aerial photo of IET. 




Fig. 7 Site plan for Hallam components. 
1

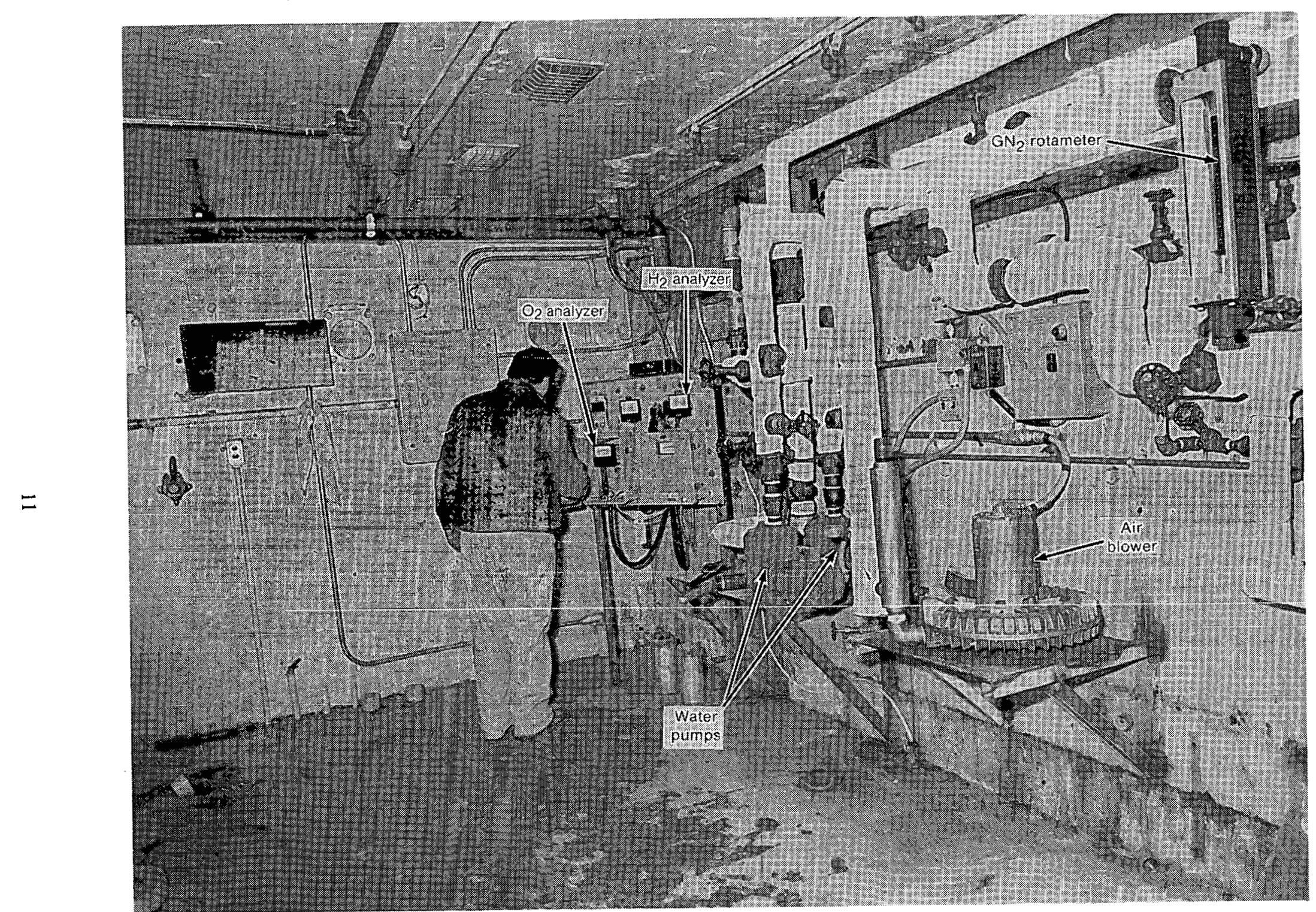

Fig. 8 Inside view of control room. 


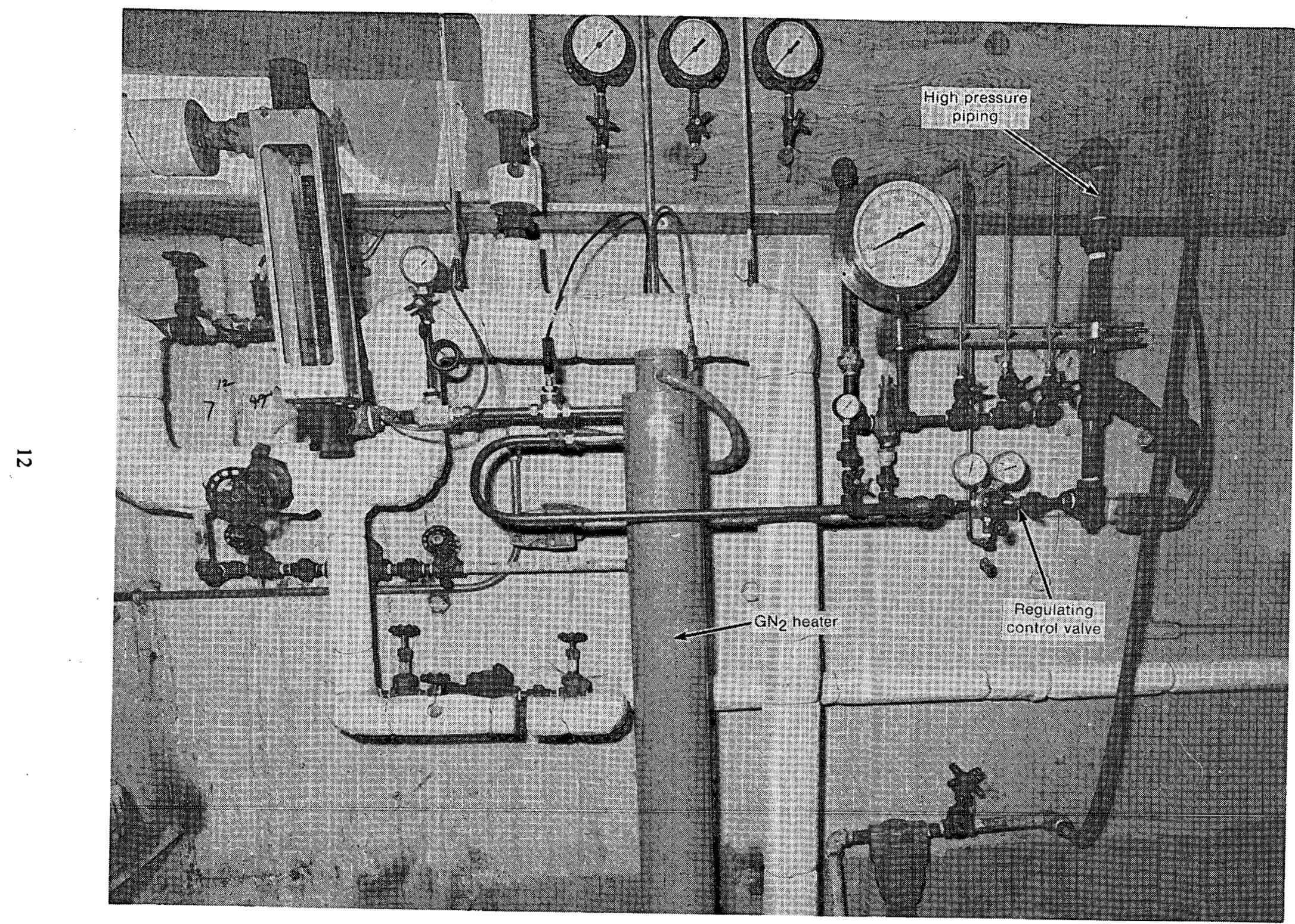

Fig. 9 Another inside view of control room.

1 


\section{ENGINEERING}

Several methods were considered to remove sodium from the components. From these, the "wetted gaseous nitrogen" $\left(\mathrm{GN}_{2}\right)$ process was selected. This method was selected primarily because it was used very successfully during decommissioning of the Experimental Breeder Reactor One (EBR-I) facility ${ }^{3}$ at INEL, and because literature sources ${ }^{4}$ indicated that others had used it successfully.

Wetted $\mathrm{GN}_{2}$ reacts with sodium (Na) producing gaseous hydrogen $\left(\mathrm{GH}_{2}\right)$ and a strong caustic $(\mathrm{NaOH})$. Thus a system was designed to incorporate this process in such a way that the Hallam components themselves served as reactor vessels. Since some of the components were radioactively contaminated, while others were not, two variations of the processing system were designed. That used for processing noncontaminated sodium was not required to have a filter system. A schematic diagram of this system is shown in Figure 10. Since radioactive effluents could not be discharged to the atmosphere, a filter system was required for processing contaminated components. A schematic diagram of this latter system is shown in Figure 11. A detailed diagram of the processing system is shown in Figure 12.

$\mathrm{GN}_{2}$ was stored in two stainless steel spherical tanks. Prior to starting the processing operation, the tanks were hydrostatically tested to $20675 \mathrm{kPa}$ (3000 psig). During operation, nitrogen was stored in them at $13784 \mathrm{kPa}(2000 \mathrm{psig})$. The tanks are approximately $1.83 \mathrm{~m}$ in diameter and hold 422 standard cubic metres of nitrogen at $13784 \mathrm{kPa}(2000 \mathrm{psig})$. The tanks were filled by a $\mathrm{GN}_{2}$ trailer, which itself was filled from the liquid nitrogen $\left(\mathrm{LN}_{2}\right)$ stand at the Loss-of-Fluid Test (LOFT) area. One full tank contained enough $\mathrm{GN}_{2}$ to process one large Hallam component.

High-pressure piping was routed from the tanks to the control room and the high-pressure gas was regulated to a low pressure. When the gas expanded from high to a low pressure, it cooled to approximately $-6.7^{\circ} \mathrm{C}$. To prevent steam condensation the gas was reheated by an electric heater to $176.3^{\circ} \mathrm{C}$ prior to mixing with the steam. The nitrogen heater can be seen in Figure 9.

Water for the wetted nitrogen process was supplied by a conventional steam generator. The steam generator has a rated output of $72 \mathrm{~kg} / \mathrm{hr}$. It was located in the IET facility in the lower level directly under the control room. The steam generator is shown in Figure 13.

Warm air is supplied to the components to dry their internals after processing. A centrifugal air compressor is used for this purpose. It is also located in the control room and can be seen in Figure 8 .

A condenser was used to condense the "caustic carryover" out of the effluent on the discharge line of the processing system. To do this, an air compressor aftercooler was borrowed from the IET equipment inventory. The condenser was an air (tube side) to water (shell side) type. It functioned very well, removing large quantities of caustic vapor. The condenser is shown in Figure 14.

A demister was used to mechanically remove any water vapor from the effluent. The unit, fabricated at the IET facility by crafts personnel, consisted of a drum with approximately $62 \mathrm{~cm}$ of compressed steel wool sandwiched in the middle. The steel wool mechanically collects droplets; the liquid then drains to a trap and empties into a 208-1 (55-gal) drum. The demister is shown in Figure 15.

A recirculating scrubber in which water was sprayed over the effluent to scrub out and remove the caustic spray was also used during the initial processing operations. However, the scrubber water became a strong caustic itself, and this greater caustic volume added to the caustic carryover problems. Thus, the scrubber was removed from the system. The scrubber is shown in Figure 16.

On exiting the demister, the effluent next passes through a separator. The separator was designed to remove water droplets from the effluent in order to protect filters located downstream. The separator was purchased from a commercial vendor. However, because of the large volume of caustic, it managed to get 


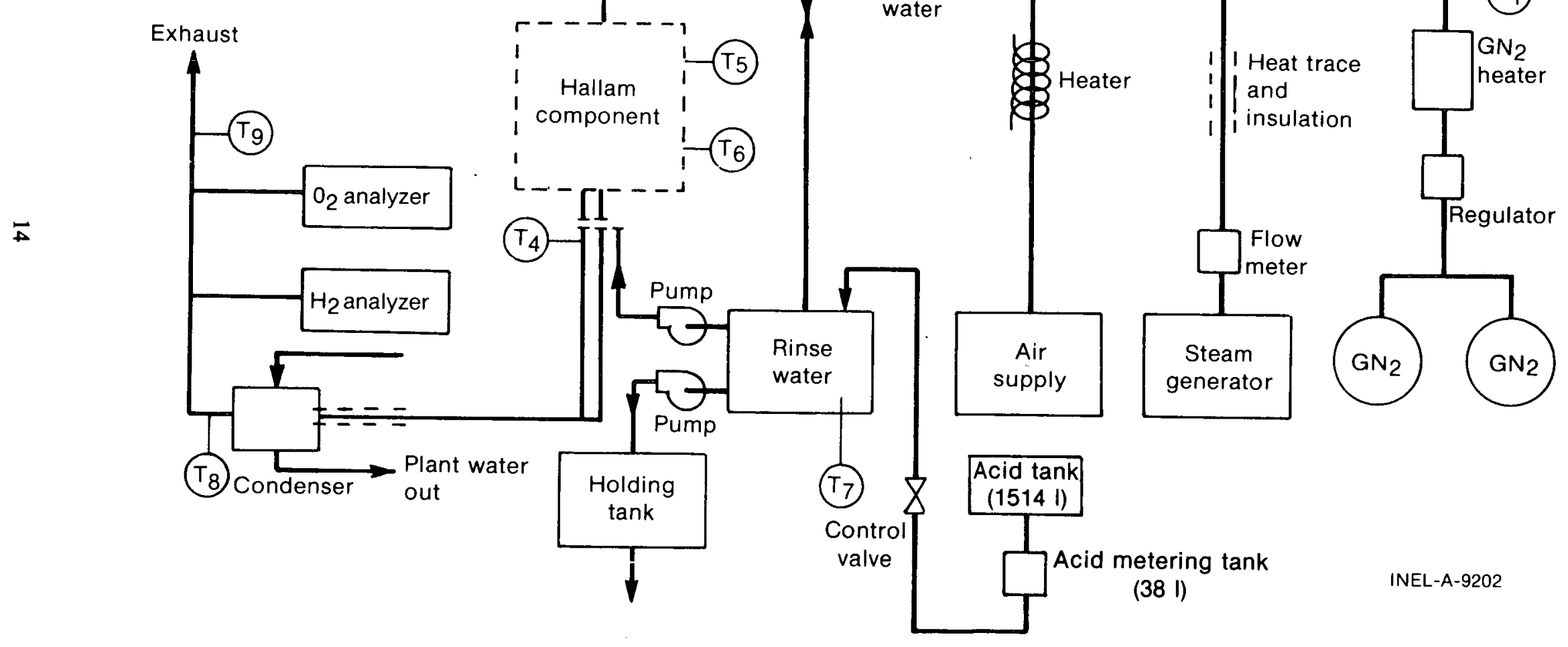

Fig. 10 Hallam processing flow path for noncontaminated components. 


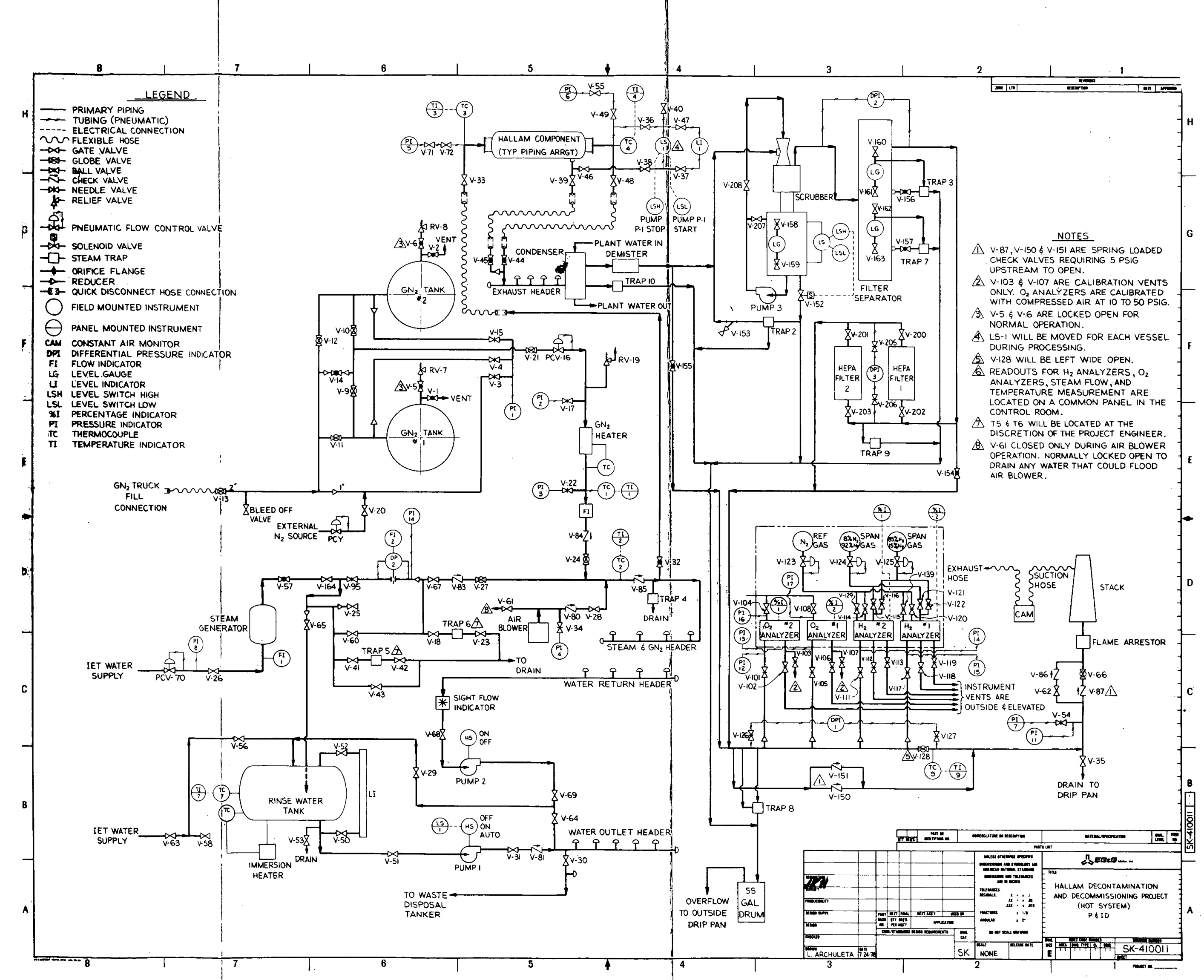




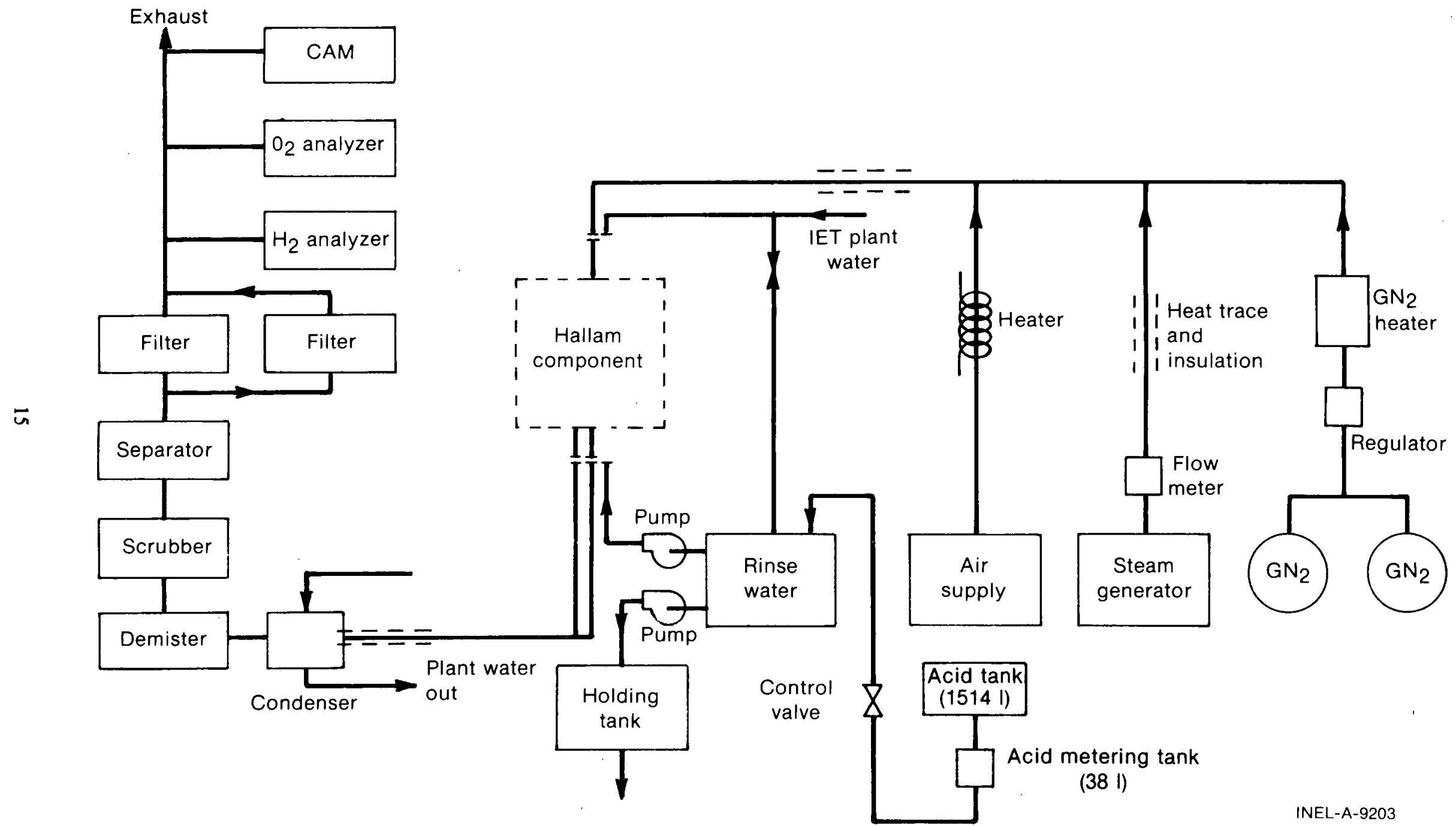

Fig. 11 Hallam processing flow path for contaminated components. 


\section{Internal Distribution}

$$
\begin{aligned}
& 1 \text { - } \text { Chicago Patent Group - DOE } \\
& 9800 \text { South Cass } \\
& \text { Argonne, IL } 60439 \\
& 1 \text { - } \text { R. L. Blackledge } \\
& \text { Idaho Operations office - DOE } \\
& \text { Idaho Falls, ID } 83401 \\
& 1 \text { - } \text { H. P. Pearson } \\
& \text { Information Processing - EG\&G } \\
& 6 \text { - } \text { INEL Technical Library } \\
& 20 \text { - Authors } \text { Apectal Internal } \\
& 29 \text { - Spental }
\end{aligned}
$$

\section{Externa1 Distribution}

$$
6 \text { - Special External }
$$

313 - UC-70 -- Nuclear Waste Management

Total Copies Printed: 377 


\section{1}

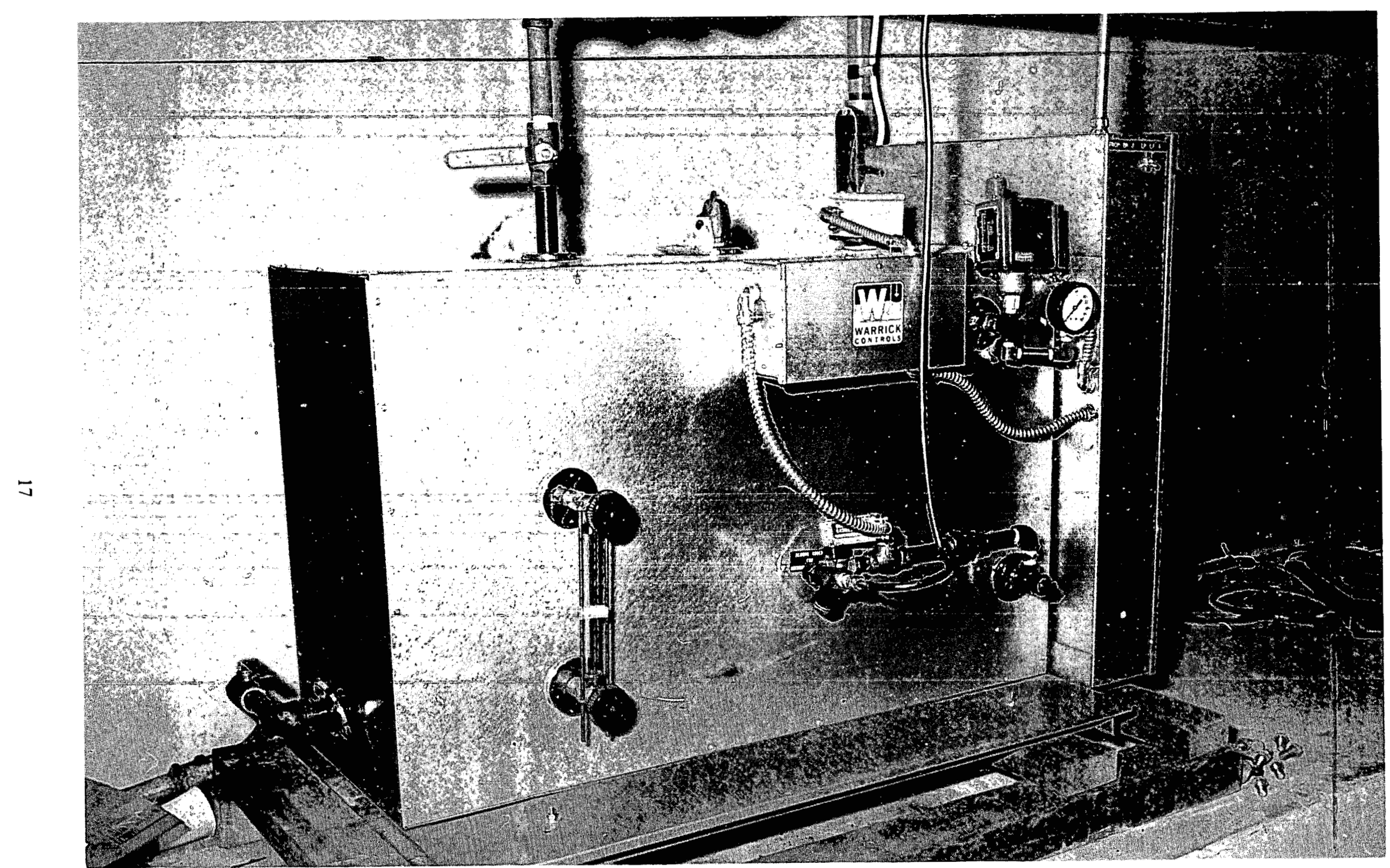

Fig. 13 Steam generator. 


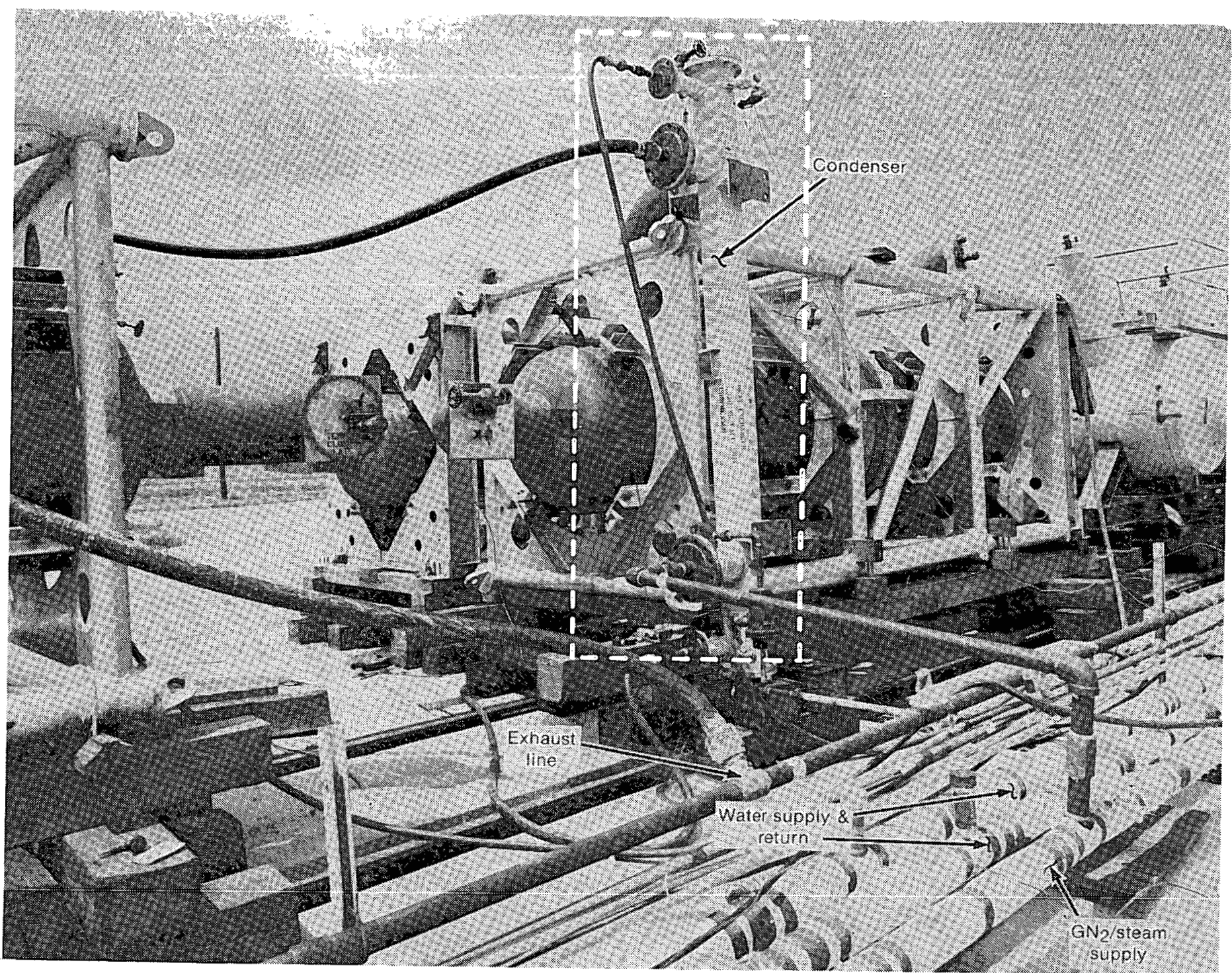

Fig. 14 Condenser. 


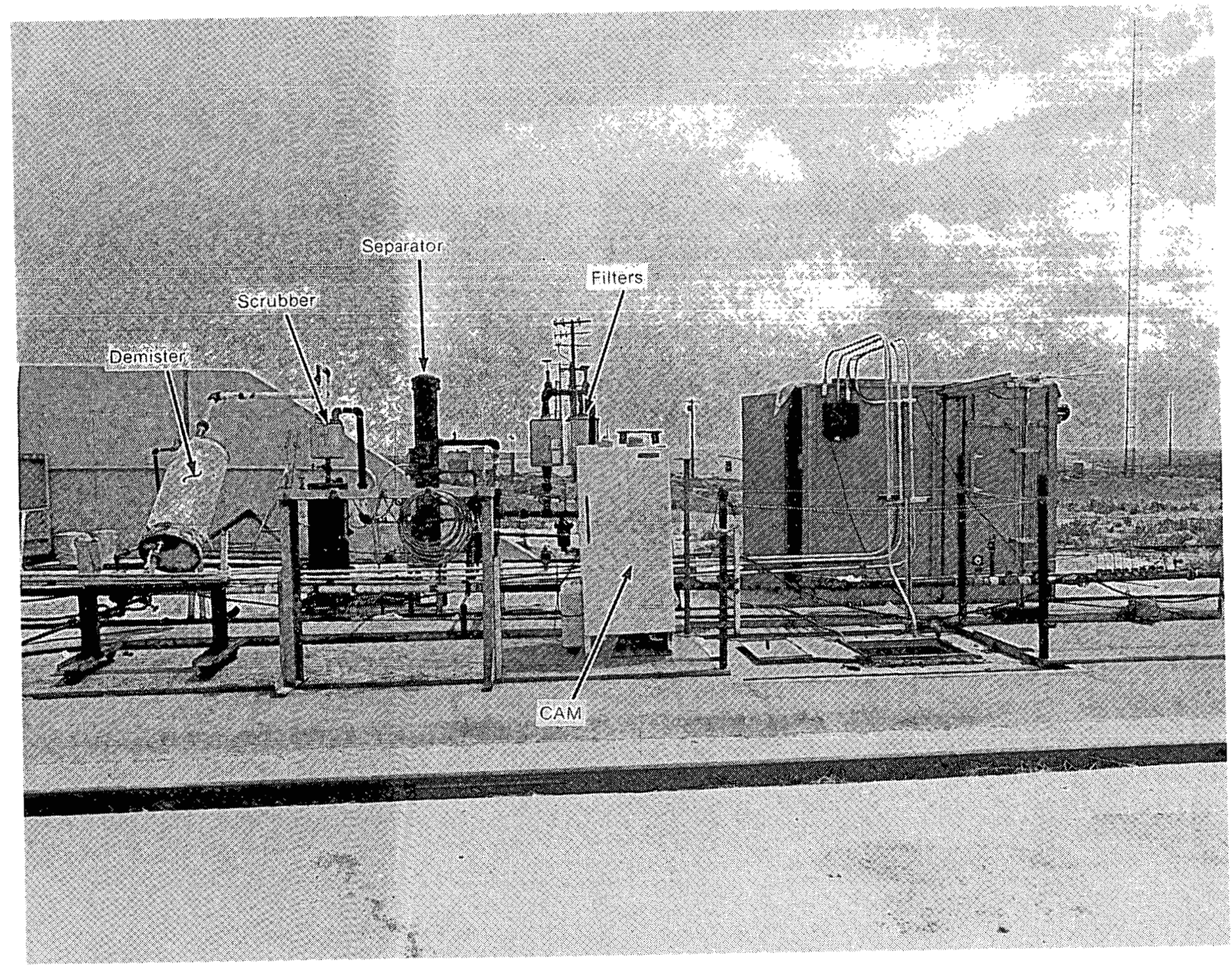

Fig. 15 View of processing system, demister, scrubber, separator, and filters. 


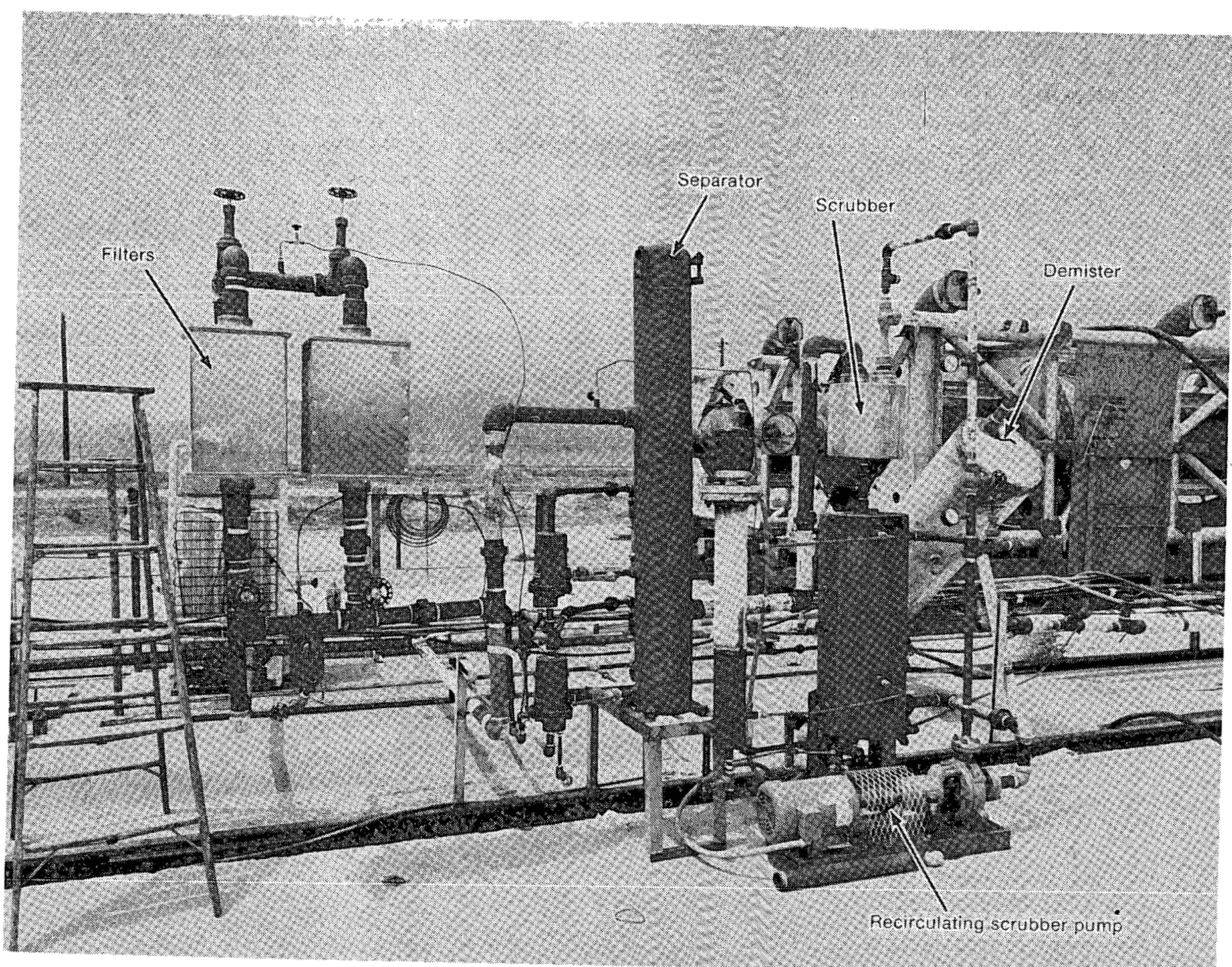

Fig. 16 View of processing system, filters, separator, scrubber, and demister. 
past the separator (prior to putting the condenser and demister into the system) and into the $\mathrm{O}_{2}$ and $\mathrm{H}_{2}$ analyzers. This required shutdown and cleaning of the analyzers. The separator is also shown in Figure 16.

The high efficiency particulate air (HEPA) filters used were capablc of stopping $99.9 \%$ of all particles 3 microns or larger. The filters were placed in the system to remove radiation contaminated particles from the effluent when processing the primary sides of the intermediate heat exchangers and the pump casings. These filters can also be seen in Figure 15.

The effluent was monitored by two types of analyzers. Oxygen $\left(\mathrm{O}_{2}\right)$ analyzers were used to indicate when the gaseous nitrogen $\left(\mathrm{GN}_{2}\right)$ purge had eliminated $\mathrm{O}_{2}$ in the vessels. The sodium/water reaction was not initiated until the $\mathrm{O}_{2}$ level was less than $1 \%$. The hydrogen $\left(\mathrm{H}_{2}\right)$ analyzer was used to monitor the sodium/water reaction (which releases $\mathrm{H}_{2}$ ). The processing was terminated when the $\mathrm{H}_{2}$ content in the discharge line was less than $4 \%$. Two $\mathrm{H}_{2}$ and two $\mathrm{O}_{2}$ analyzers were used for redundancy. The analyzers were purchased from a commercial instrumentation manufacturer and are shown in Figure 17.

A constant air monitor (CAM) was used in the system to detect radiation in the discharge line when processing the contaminated components (five primary side IHX and three pump casings). A second CAM was located on the pad area to detect any airborne contamination escaping from the system. The CAMs were provided by the EG\&G Safety Division and are shown in Figure 18. 


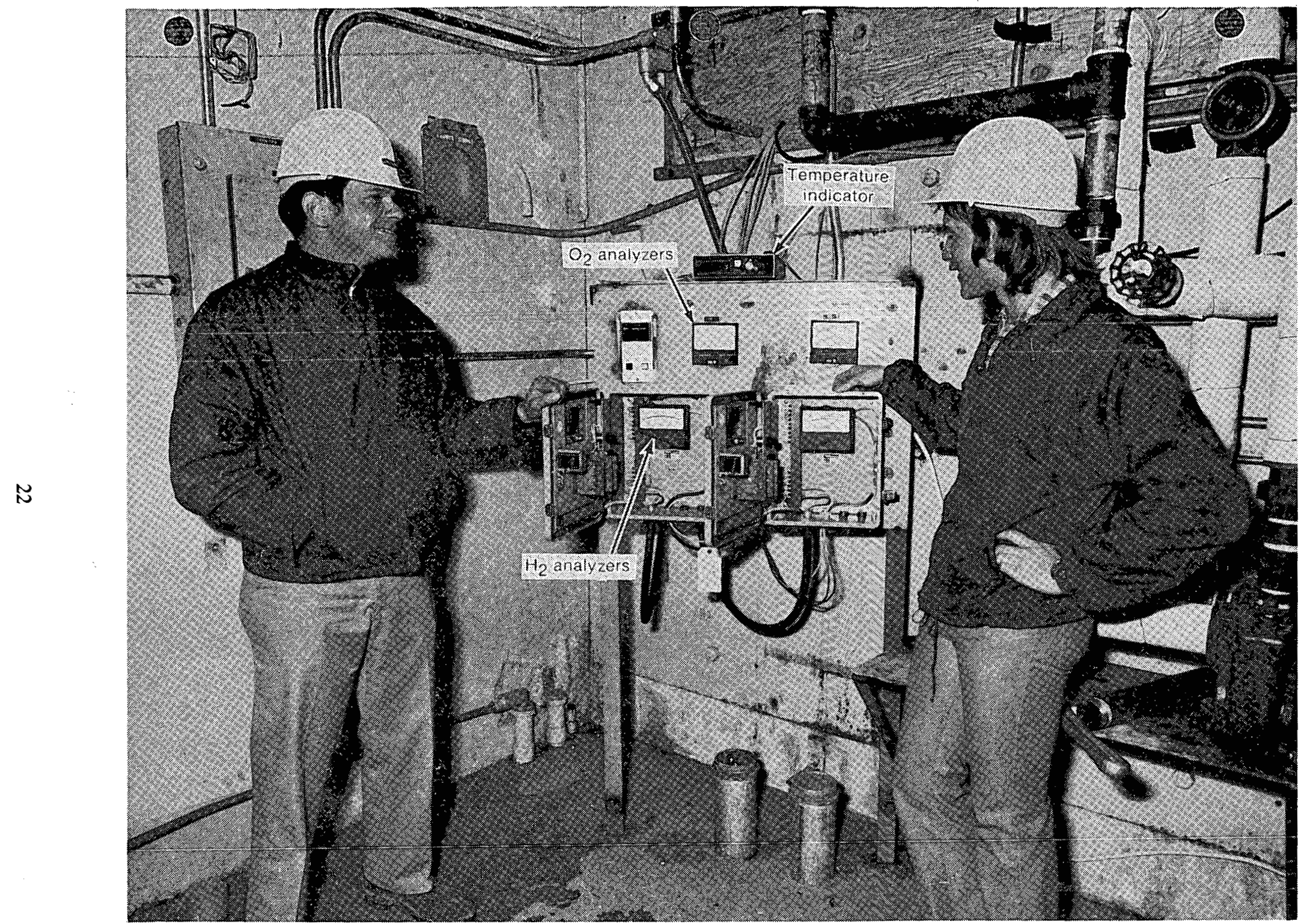

Fig. 17 Hydrogen and oxygen analyzers. 




Fig. 18 Constant air monitor (CAM) 


\section{SODIUM PROCESSING OPERATIONS}

A typical component sodium processing operation consists of:

(1) Initial preparation

(2) Sodium processing

(3) Water fill

(4) Neutralizing and draining.

The following sections discuss these steps in greater detail.

\section{INITIAL PREPARATION}

A full day is required to complete preparations to process a vessel. A level gauge and associated valves are used to shut off the pump when the component is full of water. These must be moved to each individual component before processing can start. The $\mathrm{GN}_{2}$ spheres and tank must be filled. All process lines and valving must be removed from a processed component and installed on the next component. All instrumentation and equipment must be checked, calibrated, and made ready for the processing operation. The net result of all of the required changing, calibration, and preoperation checks is that a full shift of work is required prior to starting the processing of any individual component.

\section{SODIUM PROCESSING}

All sodium processing operations are controlled by a detailed operating procedure (DOP). This helps ensure that the valves are correctly adjusted, and that the system will operate safely. All DOPs are reviewed and approved by both the Safety Division and program personnel. After the project manager, foreman, and safety engineer are satisfied that the system is complete and ready for operation, the outside pad area is evacuated, and all personnel are required to be in the underground control room and adjoining areas.

Once all personnel are in the control room, a GN 2 purge of approximately $0.71 \mathrm{~m}^{3} / \mathrm{min}[25$ standard cubic feet per minute (SCFM)] is established to purge air from the system. Oxygen and hydrogen analyzers monitor the effluent at locations immediately upstream of the exhaust stack. When an $\mathrm{O}_{2}$ concentration of $1 \%$ or less is indicated by the $\mathrm{O}_{2}$ analyzer, steam can be introduced into the vessel, thus starting the reaction. The initial steam flow of $9 \mathrm{~kg} / \mathrm{hr}$ was used for these components. This low mass flow rate is recommended because of the unknown reaction rate which could take place in a component containing unknown amounts of sodium. The $9-\mathrm{kg} / \mathrm{hr}$ flow rate was maintained for 30 minutes, then increased to $18 \mathrm{~kg} / \mathrm{hr}$, and held for another 30 minutes. This gradual increase was maintained until a mass flow rate of $72 \mathrm{~kg} / \mathrm{hr}$ was attained. This was done by increasing the rate by $9 \mathrm{~kg} / \mathrm{hr}$ every 30 minutes. The maximum capacity of the steam generator used was $72 \mathrm{~kg} / \mathrm{hr}$. The sodium reaction rate is monitored by measuring the amount of hydrogen in the exhaust gas. As a matter of interest the physical properties of the sodium processed in this manner are tabulated in Table I.

TABLE I

SODIUM (Na) PHYSICAL PROPERTIES

Melting point

Heat fusion

Boiling point

Heat of vaporization $97.8^{\circ} \mathrm{C}\left(208^{\circ} \mathrm{F}\right)$

$113276 \mathrm{~J} / \mathrm{kg}(48.7 \mathrm{Btu} / \mathrm{lb})$

$881^{\circ} \mathrm{C}\left(1618^{\circ} \mathrm{F}\right)$

$3874616 \mathrm{~J} / \mathrm{kg}(1666 \mathrm{Btu} / \mathrm{lb})$ 
Three evaporators were the first group of components processed. Figure 19 shows data obtained from a typical processing operation of one of these components. The word "typical" is used to indicate that the vessels had generally the same amount of $\mathrm{Na}$ in them, and that they should have reacted in approximately the same manner. However, due to equipment malfunctions, experimenting with the process system, and steam flow shutdowns to inspect equipment, each process varied slightly in maximum temperatures, pressures, steam flow rates, and durations. After several hours of flowing steam and hot $\mathrm{GN}_{2}$ into the components the $\mathrm{Na}$ would eventually melt $\left(\right.$ at $97.8^{\circ} \mathrm{C}$ ) and flow to the low points in the component. Steam had already condensed and collected as water in these areas. This caused high-temperature and -pressure excursions [206.8 kPa (30 psig)], and the evolution of large amounts of $\mathrm{H}_{2}$. When exit temperatures increased to levels approaching $315^{\circ} \mathrm{C}$, the steam was turned off. Steam was reintroduced when the temperatures subsided.

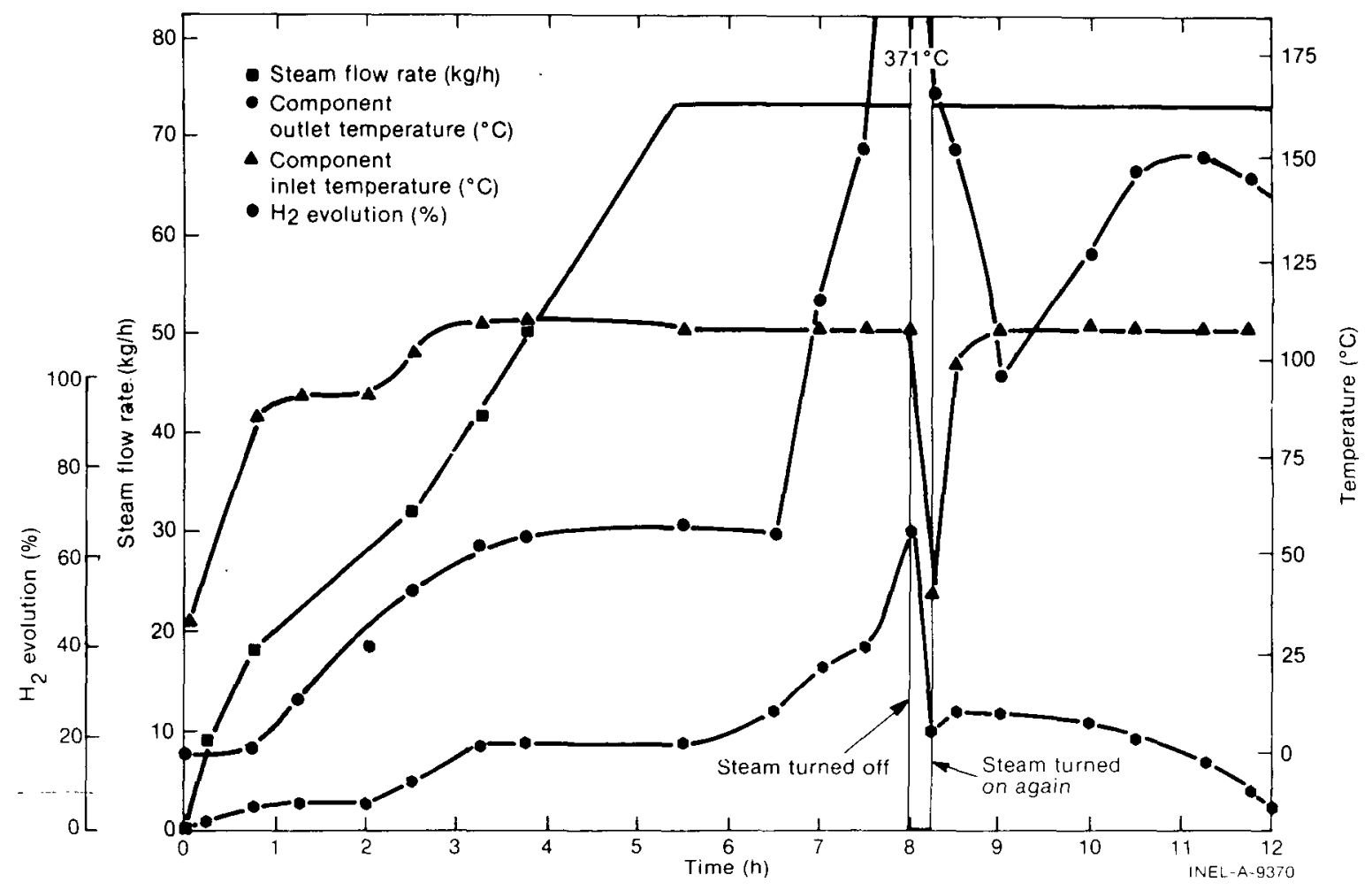

Fig. 19 Evaporator processing data.

The second group of components processed were superheaters. Figure 20 shows their typical process parameters. Again, the same high-temperature excursion occurred as the Na melted and ran to the bottom of the components.

The third group of components processed were the cold side (not contaminated) of the intermediate heat exchangers (IHXs). The IHXs contained less sodium than previous components, and the temperature excursion and increased $\mathrm{H}_{2}$ evolution were not as noticeable. This can be seen in Figure 21 which shows data typical of the intermediate heat exchangers.

The fourth group of components processed were the contaminated sides of the IHXs. However, prior to processing the radioactively contaminated sodium, several components were added to the processing system. These were:

(1) Two HEPA filters

(2) Condenser 


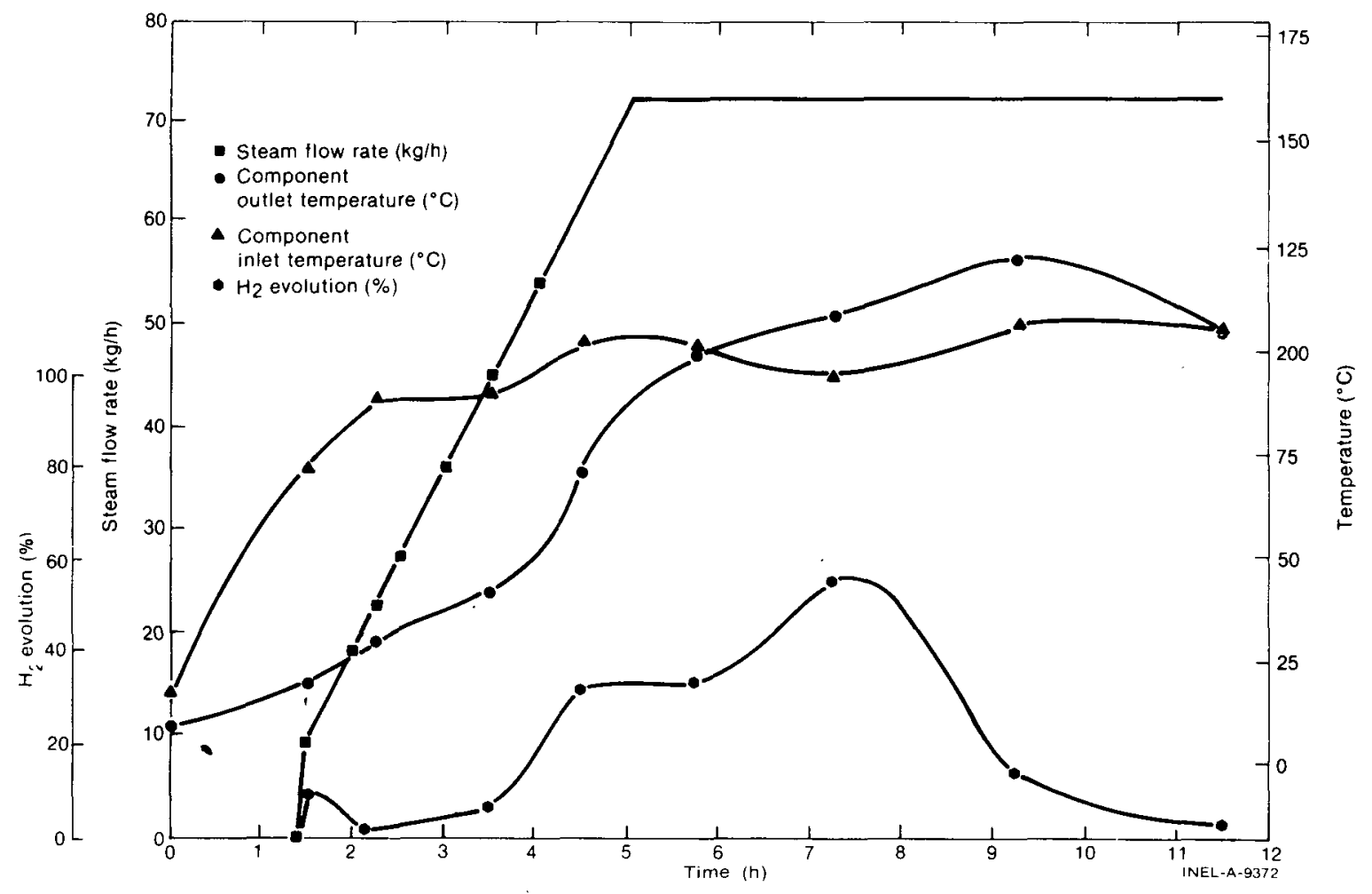

Fig. 20 Superheater processing data.
(3) Scrubber
(4) Moisture separator
(5) Demister.

The functions of these devices were explained in Section IV of this report.

After evaluating the level and type of radioactive contamination in the primary IHXs, it was determined that the components could be processed with the noncontaminated processing system. This was a result of the extremely low levels $(<1 \mathrm{mR} / \mathrm{hr}$ ) of contamination remaining in the components.

The evaluation indicated that the amount of radiation which could be released would be well within the limits allowed at the INEL. Thus, it was not necessary to have filters or other equipment in the system. However, although it was not required, the filters and equipment were installed, instrumented, tested, and evaluated. This was done to evaluate the capability of preventing contamination spread in a strong caustic environment.

The fourth group of components contained only small amounts of sodium. Thus, the $\mathrm{H}_{2}$ analyzer gave little or no indication that $\mathrm{H}_{2}$ was present in the effluent. However, as a safety precaution each component was_processed for several hours as required in the detailed operating procedures (DOP).

The last group of components processed were the pump casings. These also contained only trace amounts of 'sodium. However, they were processed, rinsed, and drained; as were all of the other components.

All components were processed with nitrogen and steam until the hydrogen level in the exhaust gas reached $4 \%$ or less. At that time water was slowly introduced into the vessels until they were full. 


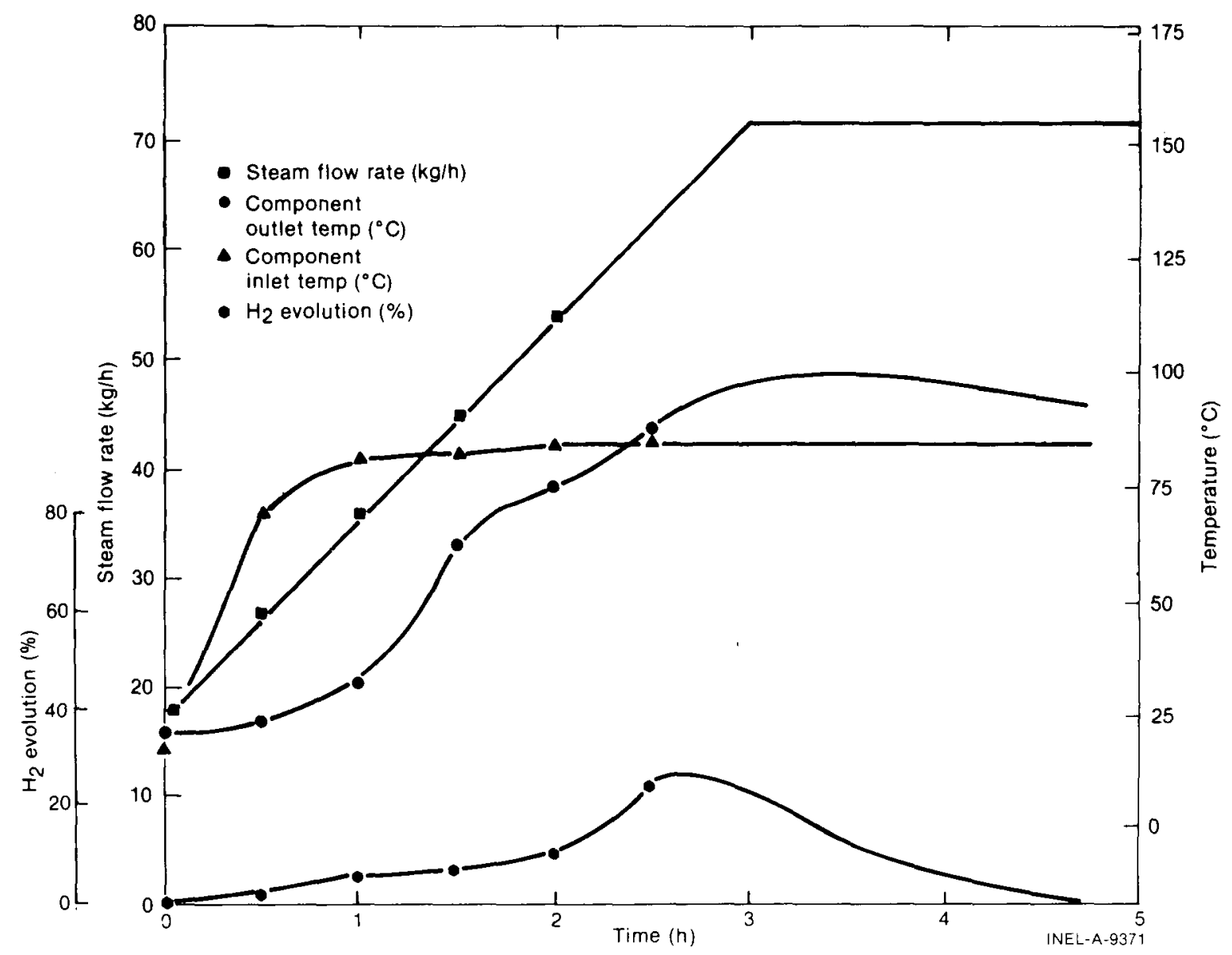

Fig. 21 Intermediate heat exchanger processing data.

\section{WATERFILL}

Immediately after processing the sodium, components were filled with water. Steam and $\mathrm{GN}_{2}$ flow were terminated and the inlet line disconnected from the $\mathrm{GN}_{2} /$ steam supply header. The inlet line was then connected to the water supply header. The outlet (vent) line is left attached to the vent header.

The vessel was then filled in accordance with the detailed operating procedure. Water was pumped into the component in quantities of $38 \mathrm{l}(10 \mathrm{gal})$ every 5 minutes until it contained 378.51 (100 gal). Then 378.5-1 (100-gal) units were pumped in at intervals of 5 minutes until the component was full. A liquid level switch was used to shut off the pump when the vessels were full. The evaporators held about 4163.51 (1100 gal), the superheaters 3407 l (900 gal), intermediate heat exchangers 1893 l (500 gal) (each side), and the pump casings 3028 I ( 800 gal). Normally, the vessels were allowed to sit full of water for 3 days. The purpose for this operation was to react any $\mathrm{Na}$ remaining in the component.

\section{NEUTRALIZING AND DRAINING}

The mixture of caustic and water in the components remained extremely corrosive. The $\mathrm{pH}$ of the water in most components was above 13.5 with some higher than 13.9. The strong caustic was not expected based upon the amount of sodium which the components were reported to contain. An acid subsystem was thus required to safely neutralize the large amounts of caustic. A 1514-l (400-gal) acid tank was obtained from the Test Reactor Area (TRA). Through titrating small quantities of caustic, it was estimated that 378.51 (100 gal) of concentrated sulfuric acid would be required to neutralize 4163.5 l (1100 gal) of caustic from 
an evaporator. This estimate proved to be very accurate. It did take 378.51 (100 gal) of concentrated sulfuric acid to bring the solution to a pH of 7.0. Figures 22 and 23 are photographs of the processing area which show the acid supply tank.

To neutralize the liquid, part of the caustic was pumped from the component to the rinse tank. Acid was drained from the 1514-l (400-gal) acid tank into the 38-l (10-gal) metering tank which was located above the 38-I (10-gal) rinse tank. A recirculating pump was used to circulate caustic from the rinse tank through the component as acid was slowly added from the metering tank. The mixing and circulating of acid is done over a period of 30 minutes. This step is repeated by adding acid in 38-1 (10-gal) increments until the pH of the solution in the component is 7.0 .

The original plan was to drain caustic from the components immediately after processing and prior to filling the component with water. For contaminated components this would result in lower volumes of contaminated waste materials which would have to be stored at the RWMC.

It was necessary to change this procedure after processing the first component. During processing the $\mathrm{Na}$ melted and ran to the lowest point in the vessel which was the caustic drain. This filled the drain and refroze, which plugged the drain. Steam could not react with $\mathrm{Na}$ in the lower portion of the drain because it formed a protective oxide crust. When it was discovered that the drains were plugged the vessel was filled with water in an attempt to break through the oxide crust and react the $\mathrm{Na}$. This was not successful.

Several components were processed and filled with water before an acceptable method was devised to remove $\mathrm{Na}$ from the drain and drain valve. A water nozzle spray was attached to the drain valve, and this proved successful in removing the sodium from this area. A schematic of the apparatus used to solve this problem is shown in Figure 24.

After neutralization the component was drained. The draining operation was accomplished by pumping the neutralized water into a large tank truck and hauling it to the TAN acid pit for disposal. This tank truck is shown in Figure 25. The component was refilled with fresh water and retested to ensure that the $\mathrm{pH}$ was 7.0. This water was also pumped to the tank truck and hauled to the acid pit for disposal. 




Fig. 22 Processing area showing the 1514-l (400-gal) and the 38-1 (10-gal) acid metering tanks. 


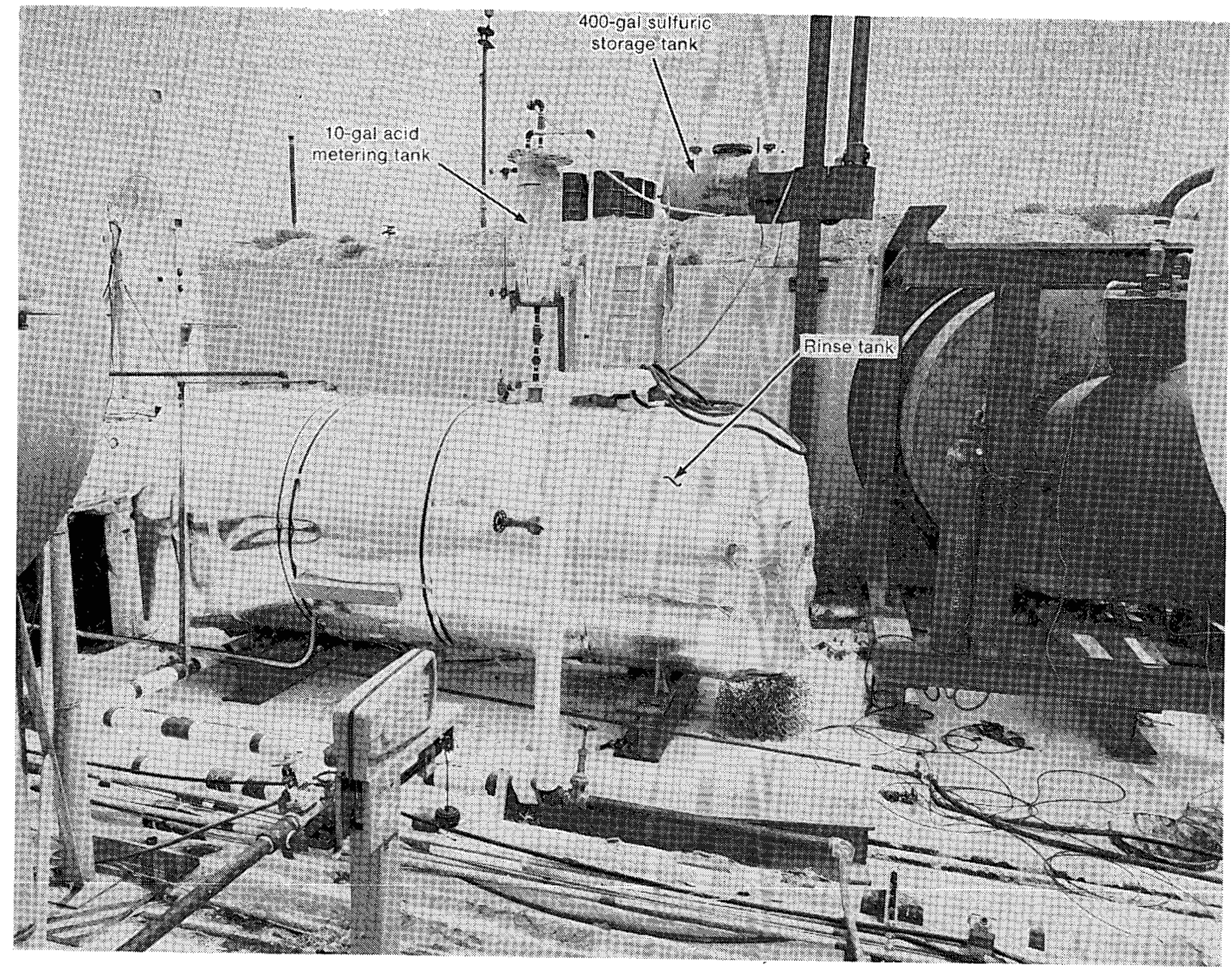

Fig. 23 Another view of the 1514-l (400-gal) and the 38-1 (10-gal) acid metering tanks. 

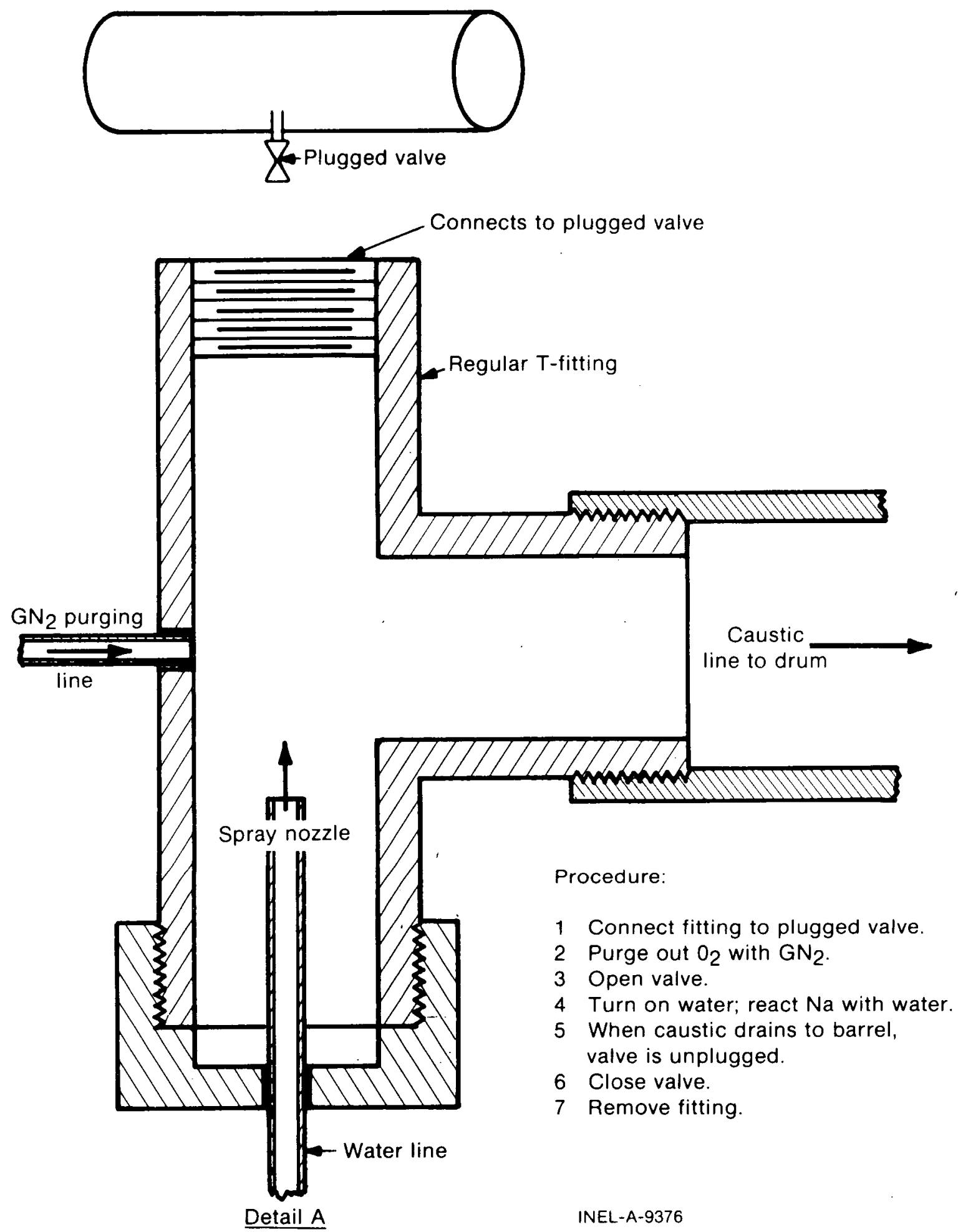

Fig. 24 Apparatus used to remove sodium from plugged valves. 




Fig. 25 Acid tank on truck. 


\section{PROBLEMS}

The purpose of this section is to describe problems which developed during the sodium processing operation. Solutions to these problems are also discussed.

\section{CAUSTIC CARRYOVER}

Large volumes of caustic are formed as the sodium reacts with water. In addition, hydrogen gas is formed, and energy is released which increases the temperature within the components. The high temperatures keep the steam and caustic in a vapor form, and the $\mathrm{N}_{2}$ and $\mathrm{H}_{2}$ carry the caustic vapors out of the component. The caustic vapors condense and plate out along the downstream piping. The extent of this problem was evaluated after the first component was processed. At that time the carryover problem was considered serious because the caustic vapors would ruin the HEPA filters during processing of contaminated components. This could potentially release contamination to the environment. The problem was recognized during the engineering design phase, and equipment was designed to remove caustic vapors prior to their reaching the filters.

A scrubber and separator were installed in the system during processing of the cold components. The scrubber was intended to scrub the effluent and remove caustic, while the separator was to remove water that the scrubber introduced. In actual practice, the scrubber was very inefficient because of the high strength of the caustic. The separator efficiency was also low due to the large quantities of vapor and water droplets contained in the exhaust line. An attempt was made to solve the problem by not using the scrubber (turning the recirculating pump off) and by installing a large condenser and demister. The condenser removed most of the water/caustic vapor from the effluent. The condensed liquid was drained to a barrel through a trap. The demister (which was downstream of the condenser) removed a small quantity of vapor, and the balance continued on to the filters destroying them as predicted. The effect of caustic on the filters is shown in Figure 26.

\section{STRONG CAUSTIC}

During the design phase, it was recognized that large amounts of caustic would be generated, but the strength of the caustic was underestimated. Caustic with a $\mathrm{pH}$ of 13.9 became distributed throughout the piping, tubing, etc., downstream of the component. This required the use of protective clothing when performing minor tasks on the system. It also caused excessive replacement or repair of equipment due to rapid deterioration.

\section{CONCENTRATED SULFURIC ACID}

Concentrated sulfuric acid was required to neutralize the strong caustic. Approximately $379 \mathrm{l}$ (100 gal) of acid were required to neutralize the 3785 l (1000 gal) of caustic contained in each component. The acid/caustic reaction generated large quantities of heat during the neutralization process. A detailed operating procedure and extreme care were required when mixing acid into the rinse tank. The recirculating pump was operated during this operation to distribute the heat through the large volume in the component. Also, the mixing was done slowly by taking 30 minutes to add 381 (10 gal) of acid to the rinse tank. Precautions necessary for handling large amounts of concentrated acid and the neutralization procedure itself resulted in considerable extra time required to complete processing of the components.

A problem also developed with the 1514-1 (400-gal) acid tank. This resulted because material in the block valves was not suitable for acid service. Two block valves were installed between the acid tank and the rinse tank whose seals were thought to contain teflon. Unfortunately, the seals were nylon. Teflon is compatable with sulfuric acid and nylon is not. The acid deteriorated the seals, and 11361 (300 gal) of acid were dumped into the rinse tank. A considerable effort was required to drain and dispose of this acid. 


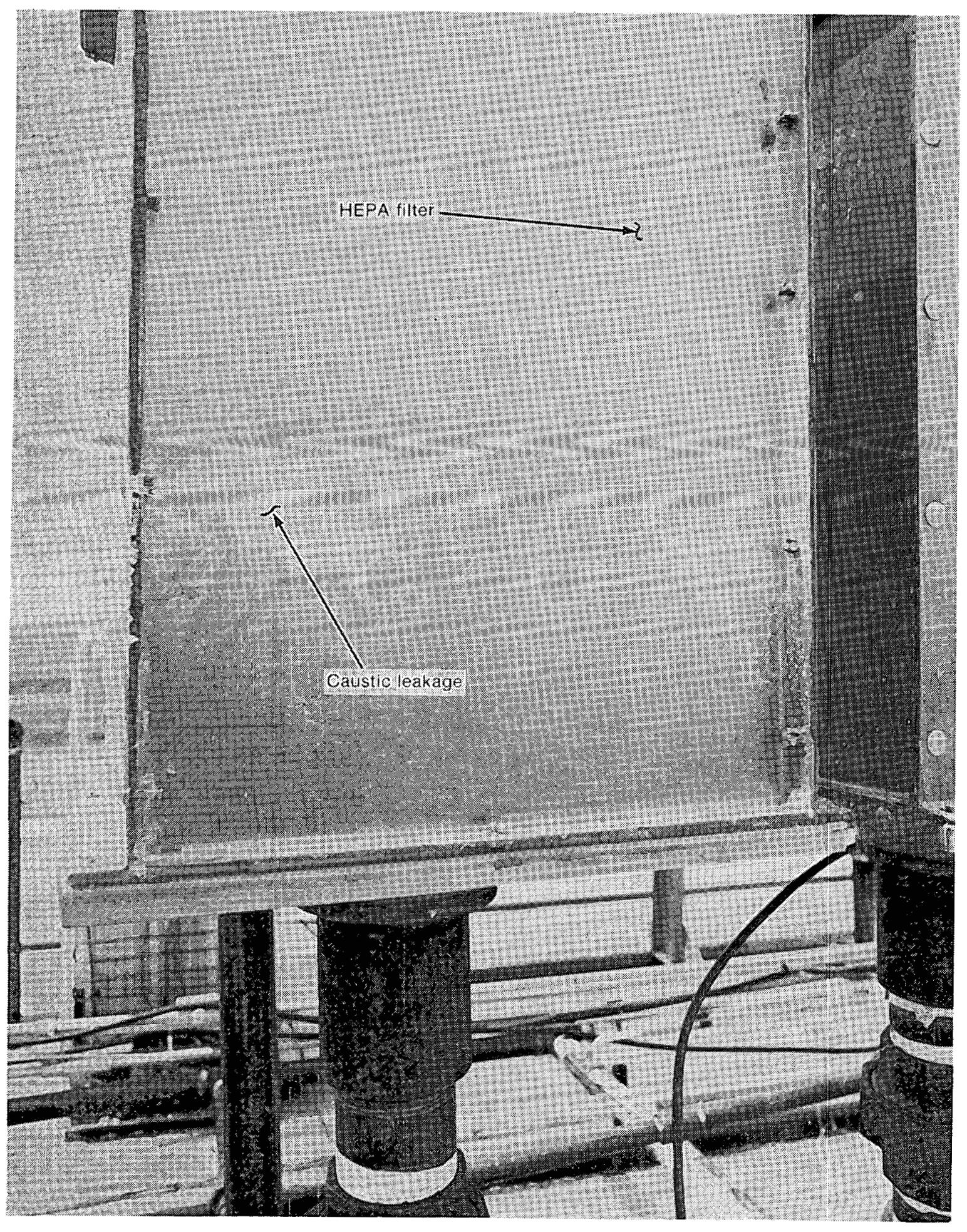

Fig. 26 HEPA filter showing caustic damage. 


\section{GN2STORAGE TANKS}

The storage tanks used to store gaseous nitrogen were originally used on the Loss-of-Fluid Test (LOFT) Program. Since it had been several years since they were used it was necessary that they be requalified by hydrotesting them to $150 \%$ [20 $675 \mathrm{kPa}(3000 \mathrm{psi})$ ] of their operating pressure $13784 \mathrm{kPa}$ (2000 psi). During the hydrotest, the flanges leaked. They were removed; new gaskets were installed; and yet they continued to leak. After removing the flange a second time and closely inspecting the tongue and groove, it was concluded that at cold temperatures a mechanical interference existed due to flange contraction. At warm temperatures the flange would expand and seal properly. The flange was machined to correct this problem, and the tanks worked properly after that.

\section{PLUgGed dRAIN VALVES}

The problem of having the $\mathrm{Na}$ melt, flow into the drains, and then refreeze, was discussed in Section V-4. Figure 24 shows the equipment and procedure for unplugging the drains. This problem increased the cost and delayed the schedule somewhat but can be avoided in the future by starting with drains which have been designed to cope with the problem. 


\section{UNUSUAL OCCURRENCES}

During the course of any sodium processing operation several potential hazards can be encountered. Proper design, operational procedures, and training can prevent these potential hazards from becoming serious incidents. Following is a listing of incidents which occurred during the Hallam project, and the reasons they occurred.

(1) Encountering Sodium During Vessel Penetration. During the component inspection phase, drain and vent holes were drilled in several components. While drilling a drain hole, metallic sodium (in a powder form) fell out of the component and caught fire. This was anticipated; and personnel were trained for such an occurrence. A catch pan previously placed under the work area caught the $\mathrm{Na}$. The man drilling the hole quickly moved away, and a fireman who was standing nearby (specifically for such an occurrence) routinely put out the fire. The $\mathrm{Na}$ was disposed of in a routine manner.

(2) Valve Plugging. In Section VI Na plugging of the drains was discussed. The first time this occurred, it was discovered that the gate valve on the drain was also plugged. The valve was carefully removed exposing $\mathrm{Na}$ in the drain hole. It was then cleaned of $\mathrm{Na}$ by putting the valve in an empty bucket and very slowly filling the bucket with water. This work was performed at a safe distance from personnel and equipment. The valve was very clean after the reaction and was reinstalled on the drain. Drains were unplugged by the procedure depicted in Figure 24.

(3) Caustic Damage. As discussed earlier, caustic carryover was a major problem. This problem was the basic cause of two incidents. The quick disconnect coupling for the flexhoses contained metals which were attacked by the caustic. After five components were processed, the disconnect coupling was eaten away by the caustic, and the coupling failed when the component was about $138 \mathrm{kPa}(20 \mathrm{psig})$. The hose and coupling were rated and tested to $689 \mathrm{kPa}$ (100 psig). The inlet nozzle flexhose blew off, and caustic was blown over the local area. The component had a large volume, and at $138 \mathrm{kPa}(20 \mathrm{psig})$ it took several minutes for the pressure to stabilize. The pad was cleaned up and neutralized, and work went on as usual. This problem was anticipated, and stainless steel couplings had been ordered at the time the first component was processed. However, a long delivery time made it necessary to use the old fittings longer than desired. New stainless fittings were used as soon as they could be obtained, and this problem was eliminated.

(4) Safety Procedures. At the start of processing, a $\mathrm{GN}_{2}$ flow is established to purge out any air in the system. While processing one of the vessels, water in the flexhose created a trap. The operating pipe fitter closed the system valve on the component to disconnect the flexhose to drain it. The closed valve caused the $\mathrm{GN}_{2}$ flow to rapidly decrease. An electrician in the control room noted the flow rate decrease and became concerned that the $\mathrm{GN}_{2}$ heater coils would burn up with a lack of flow. He turned the flow control valve to increase flow. This over-pressurized the glass cased rotometer, and the meter burst. The electrician was touching the meter with his chest when it burst but suffered nothing more than a bruised muscle. Following this incident a procedure change was initiated which controlled valve setting changes, thus eliminating the recurrence of such a problem.

(5) Caustic Exposure To Personnel. A second problem occurred during processing when pressure transients were generated as a result of Na reacting violently with steam. One of these pressure spikes forced several ounces of strong caustic into the $\mathrm{O}_{2}$ analyzer, thus damaging the analyzer. During routine inspection of the analyzer by an instrumentation technician, the liquid caustic spilled on the technician. The man was not hurt, and the spill was cleaned up. 
(6) Caustic Spills. After processing the primary side of an IHX, the unit was filled with water. The operations crew then started to move the piping, etc., to the next IHX to be processed. This IHX required drain valves, so the crew removed the drain valve from the secondary side of the IHX (which just had the primary side processed). When the valve was removed, caustic drained from the drain. Apparently, there were tube leaks in the IHX, and many gallons of caustic leaked from the primary to the secondary. After approximately $189 \mathrm{l}(50 \mathrm{gal})$ drained to the pad, the vent was closed which slowed the draining. The crew put on protective clothing and capped the drain. The spilled caustic was neutralized and cleaned up in a routine manner.

(7) Acid Leaks and Spills. During the processing operations the sulfuric acid weakened the seals of two block valves. This eventually allowed the acid to drain into the water rinse tank. The valves were opened in the control room so the pumps could recirculate the caustic through the rinse tank. This allowed the sulfuric acid to drain to the recirculation pump. The acid combined with water and residual caustic, thus generating heat. The caustic and acid had already weakened seals in the pump, and the thermal expansion due to the heat caused acid to spray out of the pump through the seals. One operator was hit by the spraying acid but quickly washed it off. He was not injured. The acid was routinely cleaned up and neutralized.

The block valves were thought to contain teflon seals (which are recommended for sulfuric acid), however, the seals were nylon (which are not recommended for sulfuric acid). These were replaced by valves containing teflon seals. 


\section{POSTPROCESSING INSPECTION}

Following the sodium processing, neutralizing, rinsing, and draining operations the Hallam Reactor components were opened for inspection. This inspection assessed the effectiveness of the processing operation and determined the final state, with respect to retained sodium and radioactive contamination, of the component internals.

Prior to actually opening the components they were again filled with water and allowed to stand in this filled condition for several days. The components (vessels) were then drained and cut open. Cutting was accomplished using an air operated (pneumatic) power saw which automatically traveled along a chain placed around the vessels. This cutting operation is shown in Figure 27, which shows the end being cut from one of the superheaters. Cutting rate for these heavy metal vessels was about $2.5 \mathrm{~cm} / \mathrm{min}(1 \mathrm{in} . / \mathrm{min})$.

All vessel cuts were performed safely and efficiently using this method. The resulting cut on the superheater can be seen in Figure 28, which shows the inside of this vessel as it was opened. A closeup view of the tubesheet in the end of this vessel is shown in Figure 29.

Throughout the inspection, component internals were found to be clean and free of residual sodium. Examples of this can be seen in Figures 30 and 31. Respectively these are the tubesheet and section through the tubes of an intermediate heat exchanger.

After the vessels were cut with the pneumatic saw, tube bundles were then cut using a specifically built metal cutting band saw. All internal tubes were visually inspected for retained sodium. None of the conventional tubes contained sodium.

Special tube connections in the superheaters and steam generators did contain unreacted sodium however. These appeared in the form of a metal bellows which fit tightly over the end of the tubes. Sodium trapped between the inside diameter of the bellows and the outside diameter of the tubes could not be reached by water during the processing, and thus had not reacted. A photograph of an array of these bellows assemblies is shown in Figure 32.

Removal and sectioning of the bellows assemblies revealed small amounts of unreacted sodium such as shown in Figure 33. With the exception of these small amounts of entrapped sodium, the remainder of the vessel internals were sodium free.

Components such as the heat exchangers and primary pump cases, which were radiologically contaminated, were also inspected to determine the extent of this type of contamination. In general, these components were contaminated with Co-60 and Cs-137 to levels of less than $1 \mathrm{mR} / \mathrm{hr}$. Because of the complex geometry (tube bundles) within these reactor components, decontamination would be either impossible or at least impractical. For this reason no attempt was made to decontaminate those components which were radiologically contaminated.

As a result of the postprocessing inspection it was concluded that the wet nitrogen process used was adequate for gross removal of sodium. However, sodium trapped in small annuluses may not be reacted. Thus, if equipment having complex geometries or close tolerance components is to be processed with wet nitrogen, then a thorough inspection should be performed prior to releasing the equipment for unrestricted use. 


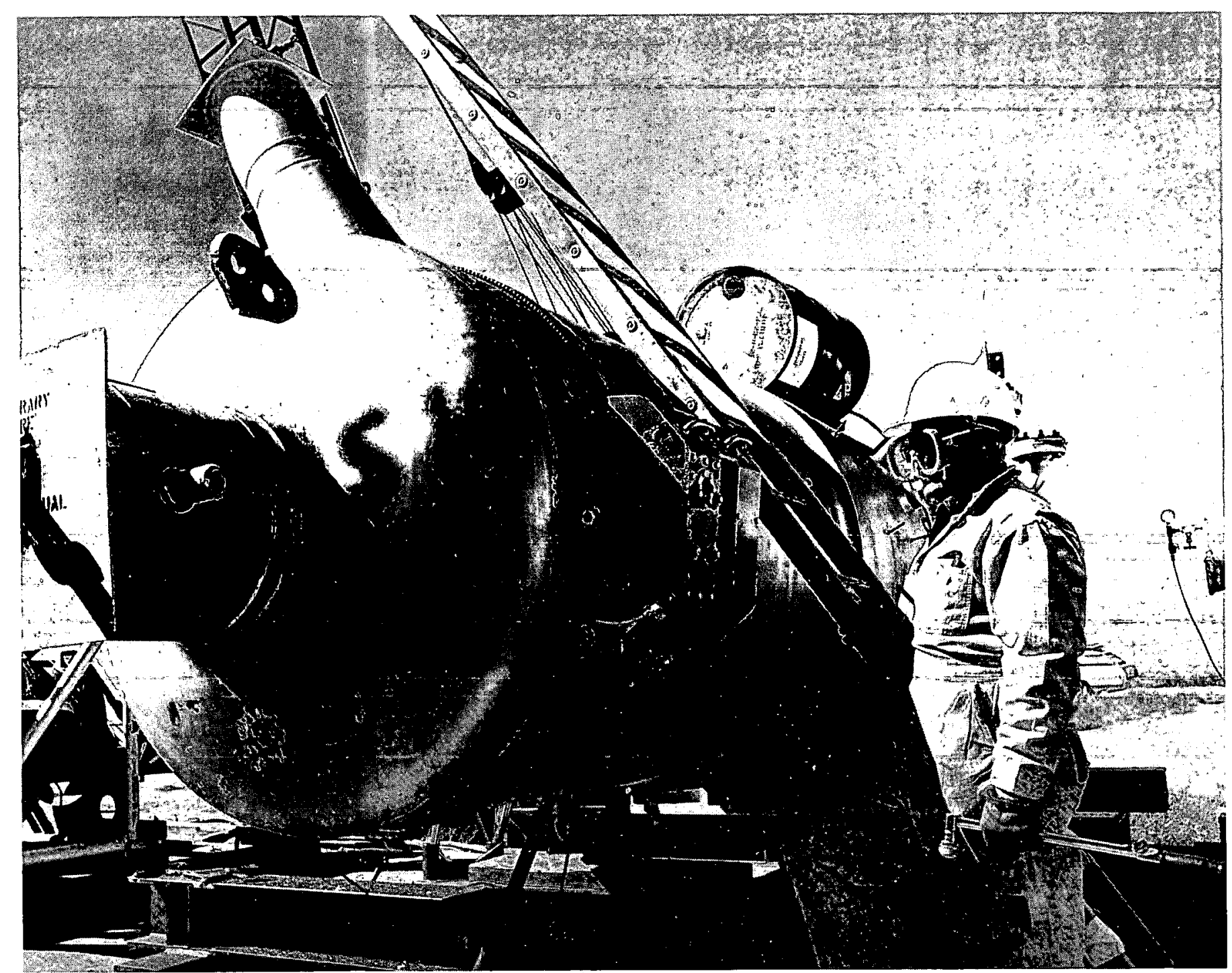

Fig. 27 Pneumatic saw cutting end of superheater. 


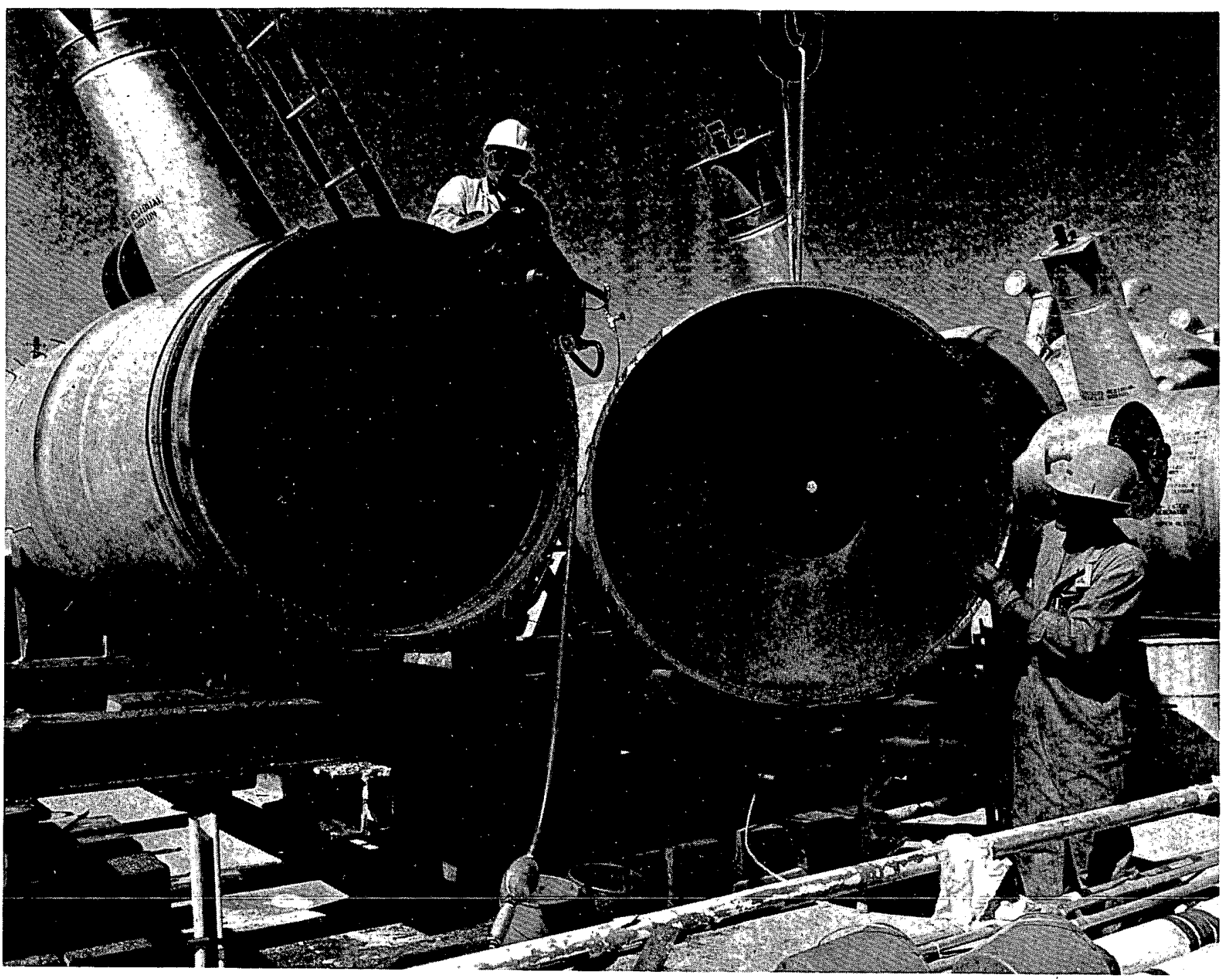

Fig. 28 Inside of superheater as it was opened. 


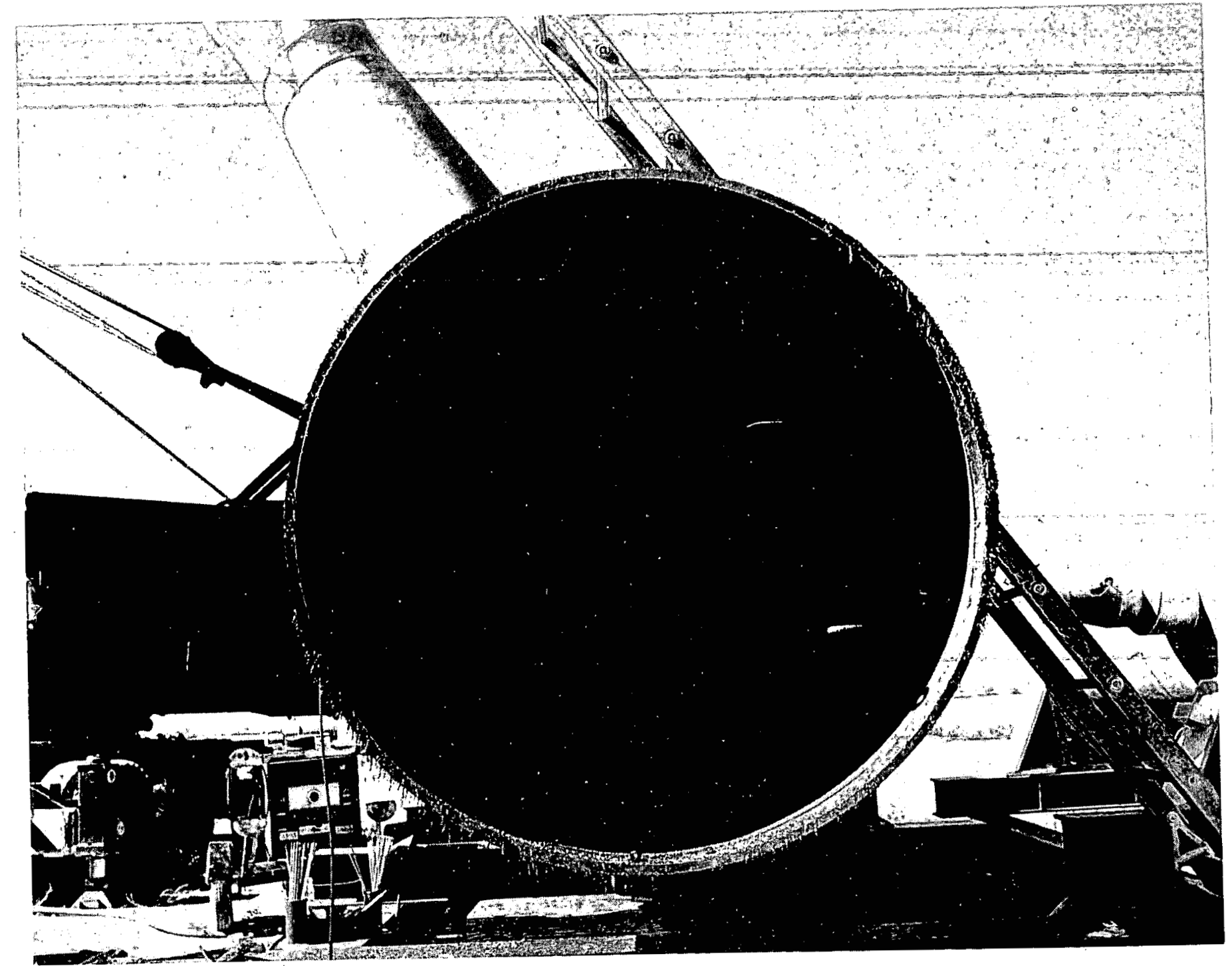

Fig. 29 Closeup of tubesheet in the end of a superheater. 


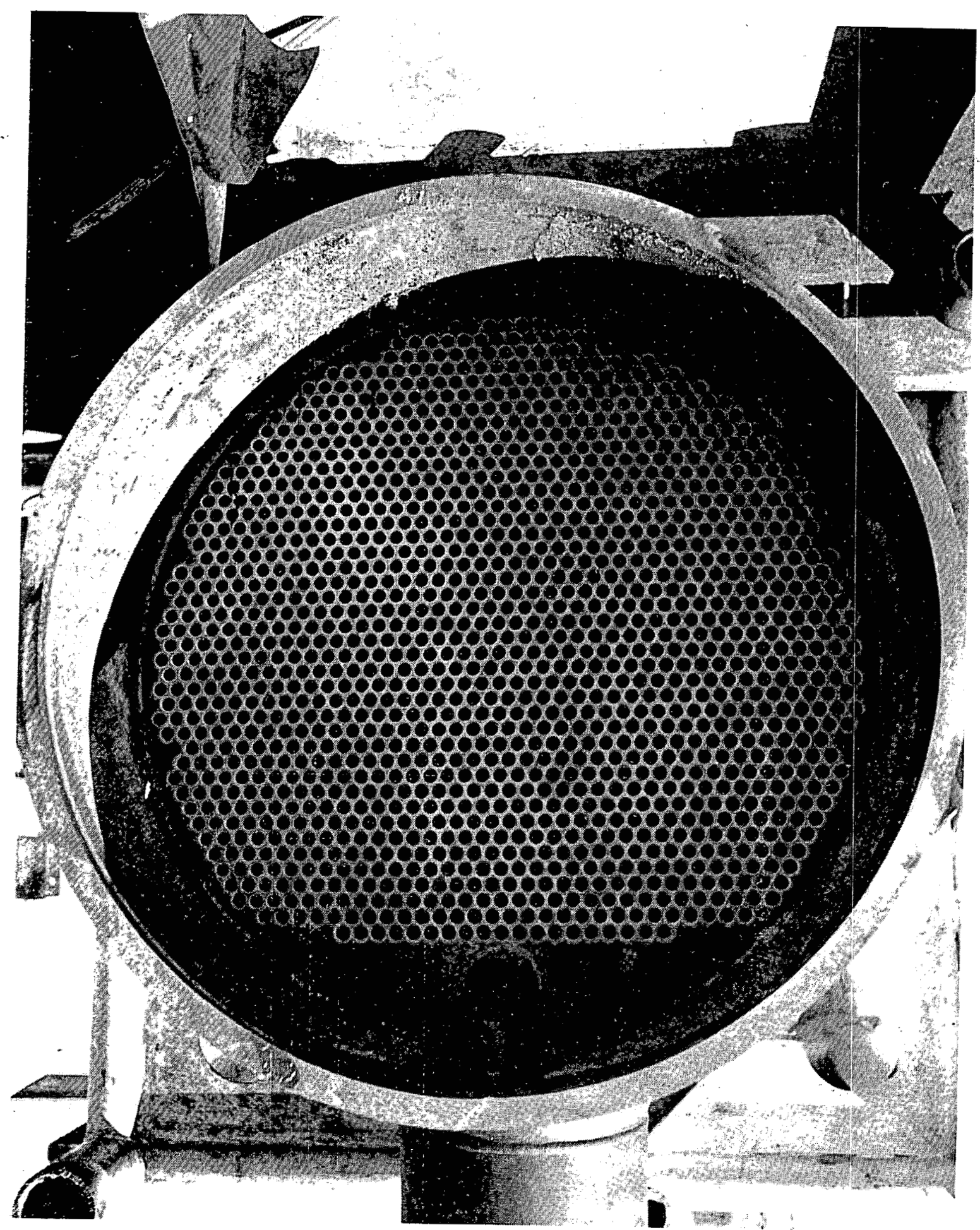

Fig. 30 Tubesheet of an intermediate heat exchanger. 




Fig. 31 Section through intermediate heat exchanger tubes. 

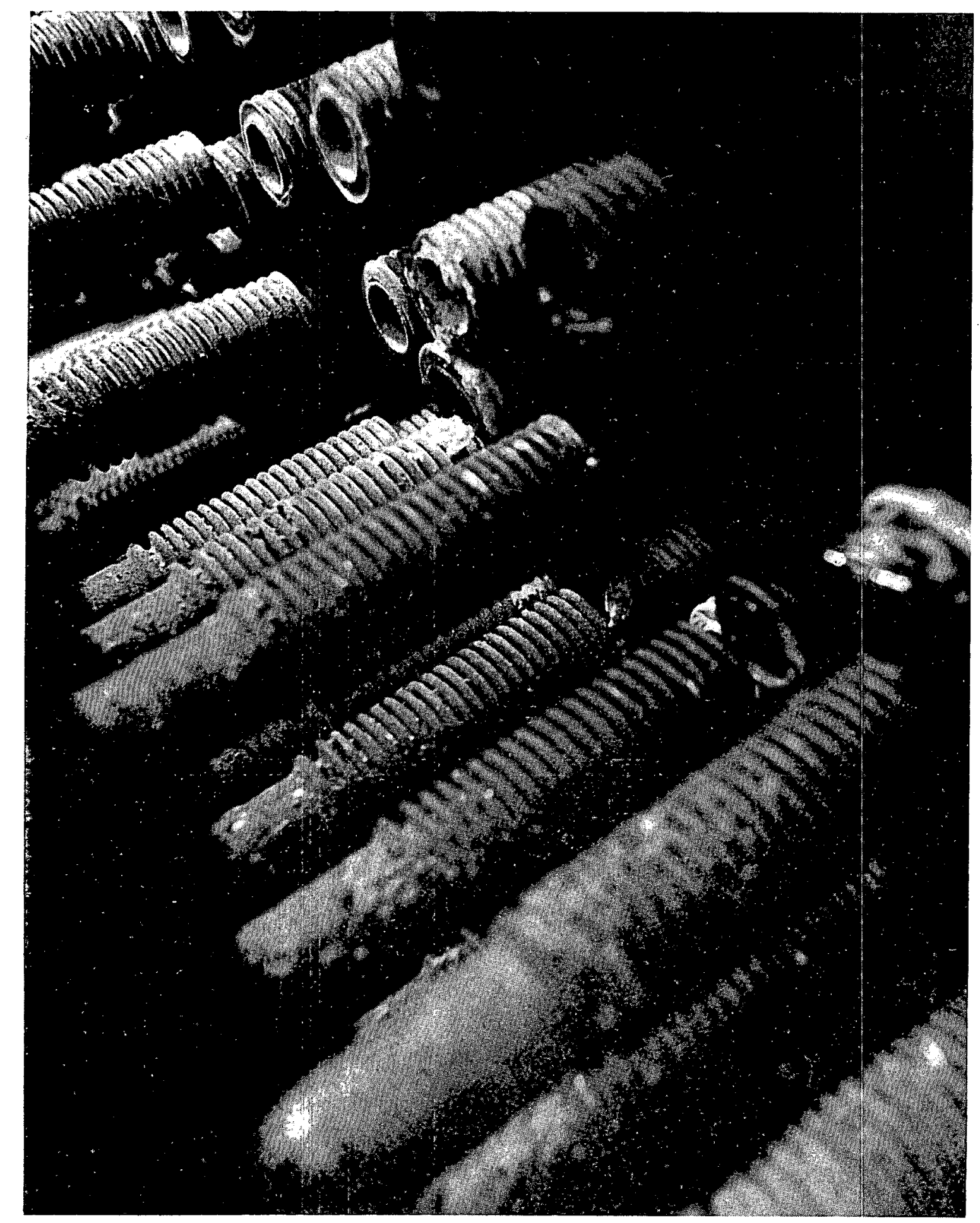

Fig. 32 An array of bellows assemblies containing unreacted sodium. 




Fig. 33 Bellows assembly sectioned to show unreacted sodium. 


\section{DISPOSITION OF THE COMPONENTS}

Based upon the results of the postprocessing inspection, decisions were made relative to the final disposition of the Hallam components. With the exception of some pump components, all radioactively contaminated components were shipped to the Radioactive Waste Management Complex (RWMC) at the INEL for disposal. This included five intermediate heat exchangers, three primary pump cases, and a pump diffuser and impeller.

Two pump diffusers and two impellers were obtained by Atomics International and shipped to their facility in Canoga Park, California. All of these components contained residual beta-gamma contamination at levels to about $2 \mathrm{mR} / \mathrm{hr}$.

The remaining components (three superheaters and three steam generators) did not contain radioactive contamination, but did contain small amounts of residual sodium. Although only small amounts of sodium were present in these components, the location and construction of the components made it impractical to remove. Thus these components were stored at an INEL landfill area and were not released for unrestricted use.

External structures and parts which were not radioactively contaminated were cut from the components and disposed of as scrap metal. This resulted in approximately $45000 \mathrm{~kg}$ (50 tons) of salvaged metal. 


\section{BUDGET AND SCHEDULE}

The Hallam component sodium removal project was started in October 1977 and completed in November 1978.

Design and preparation activities, including the writing of the project plan, safety evaluation, and detailed operating procedures, required approximately 5 months to complete. System fabrication and checkout required an additional 3 months. Actual sodium processing operations required 4 months to complete. Following completion of processing of sodium in the components, cleanup of the area and inspection of the component internals was undertaken. This work required approximately an additional 4 months to complete.

Major activities of the Hallam components project can be seen in the schedule shown in Figure 34 . Major milestones and durations of various phases of the project are shown in this figure. As can be seen, this entire project was completed in slightly over 1 year.

The original budget for this project was $\$ 428000$ which did not include disassembly and inspection of the components. An additional $\$ 20000$ was later added to cover the cost of the inspection work, thus bringing the total project costs to nearly $\$ 450000$. Approximate costs of major phases of the project were as shown in Table II.

A graph of project costs as a function of time is shown in Figure 35. Major project milestones are also shown on this graph as reference points to indicate work completed at various times. 


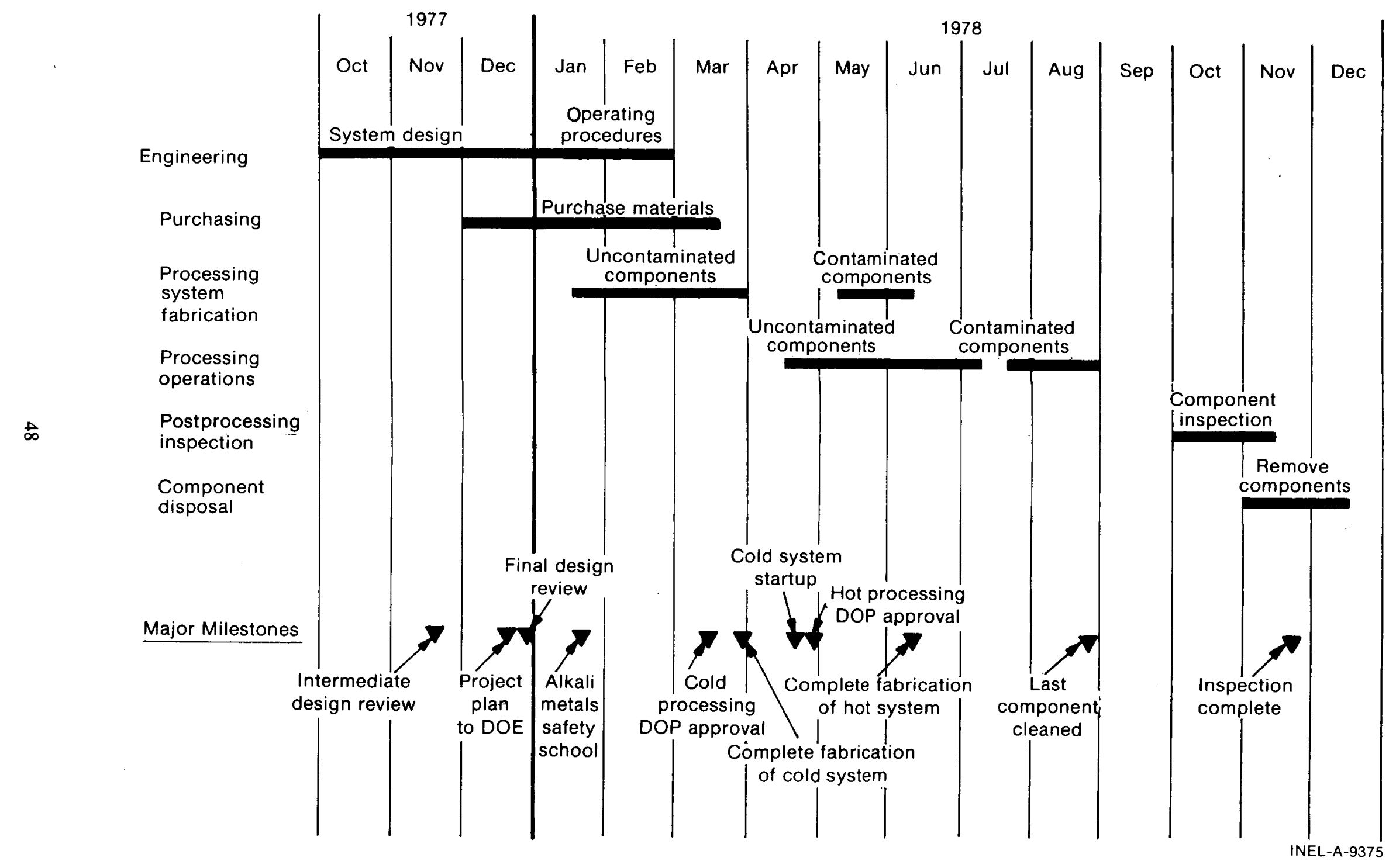

Fig. 34 Schedule and major milestones. 


\section{HALLAM PROJECT COST SUMMARY}

\begin{tabular}{lc}
\hline \multicolumn{1}{c}{ Function } & $\begin{array}{c}\text { Approximate Cost } \\
(\$ 1000)\end{array}$ \\
Project management & 83 \\
Engineering services & 73 \\
Processing system fabrication & 147 \\
Processing operations & 125 \\
Component inspection & 20 \\
\hline
\end{tabular}

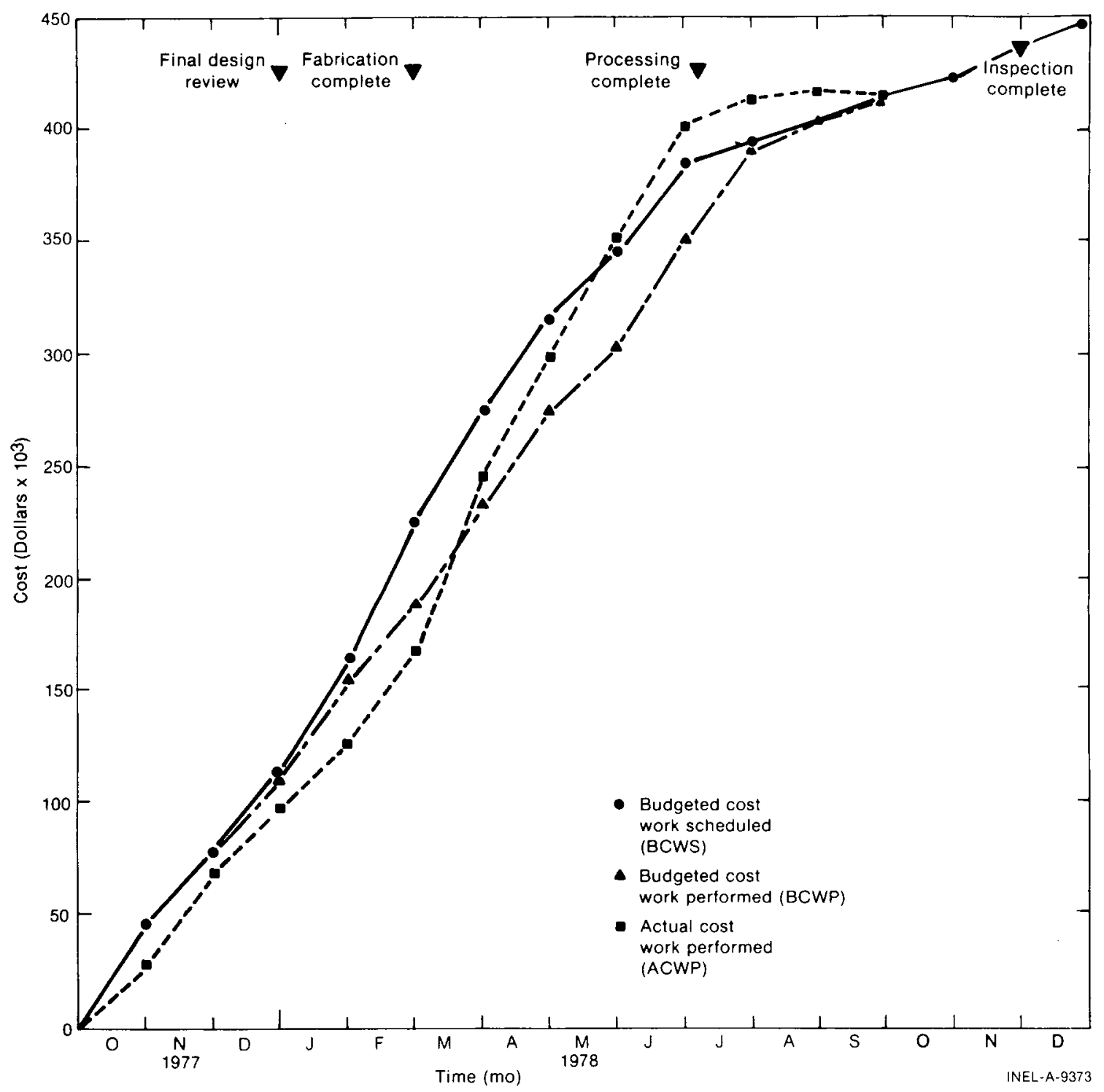

Fig. 35 Cost and schedule performance. 


\section{XI. 'CONCLUSIONS AND RECOMMENDATIONS}

Based on information derived from the design, operations, and inspection phases of this project, several conclusions were reached. These can be summarized as follows.

(1) The wet nitrogen process performed well reacting all sodium except for small amounts located in small confined spaces.

(2) By exercising the proper precautions (design reviews, safety evaluations, detailed operating procedures, etc.), the process can be made controllable and safe.

(3) Handling and neutralizing large amounts of strong caustic should be expected and provided for. For this project the volume of the caustic solution was approximately three times the volume of the components.

(4) All operations personnel must be fully trained, provided with the proper tools and equipment, and must conduct the operation using formal detailed operating procedures.

(5) The processing system should be constructed using welded joints wherever possible.

(6) Caustic carryover throughout the system is a problem, and great care must be exercised to prevent contamination spread if radioactive materials are being processed. The scrubbers, demisters, and filters used in this system were not completely effective in eliminating caustic carryover. Contamination spread was prevented however.

(7) Because of the possibility of unreacted sodium remaining in crevices or tight places, a thorough inspection should be performed prior to releasing the equipment for unrestricted use. 


\section{REFERENCES}

1. Atomics International, Report on Retirement of Hallam Nuclear Power Facility, AI-AEC-12709 (May 1970).

2. W. L. Random, Destructive Examination of a Hallam Nuclear Power Facility Intermediate Heat Exchanger, IN-1477 (April 1971).

3. E. W. Kendall and D. K. Wang, Decontamination and Decommissioning of the EBR-I Complex, ANCR-1242 (July 1975).

4. N. R. Challew and F. A. Cafasso, Treatment and Handling of FEFPL Sodium Waste Generated in $H F E F$, Argonne National Laboratory (July 1974). 